\title{
Neutron dosimetry*
}

\author{
W.G. ALBERTS**, J.M. BORDY***, J.L. CHARTIER***, R. JAHR**, \\ H. KLEIN**, M. LUSZIK-BHADRA**, F. POSNY***, \\ H. SCHUHMACHER**, B.R.L. SIEBERT**
}

(Manuscrit reçu le 18 novembre 1994)

ABSTRACT Neutron dosimetry is of practical relevance in a wide energy range of at least ten orders of magnitude. However, the dose quantities used in radiation protection are not directly measurable. This is mainly due to the variable quality of neutron radiation, expressed by radiation weighting factors (in the effective dose) or quality factors (in the dose equivalent). In spite of considerable progress in neutron dosimetry there is no dosemeter which is capable of measuring neutron doses independently of the neutron spectrum with adequate accuracy. A review is given of dose quantities, calibration methods and procedures to determine the dose at workplaces with instrumentation of limited capability. The properties of these instruments including area dosemeters, individual dosemeters and spectrometers are reviewed and increasing demands discussed. As a conclusion, there is a need for further research, development and exploration of workplace conditions.

RÉSUMÉ En dosimétrie des neutrons, les situations pratiques rencontrées couvrent un large domaine d'énergie s'étendant sur plus de 10 décades. En outre, les grandeurs dosimétriques utilisées en radioprotection ne sont pas directement accessibles à la mesure. Ce dernier point est principalement dû à la variation de la "qualité" du rayonnement neutronique, exprimé au moyen des facteurs de pondération radiologiques (pour le calcul de la dose efficace) et des facteurs de qualité (pour le calcul de l'équivalent de dose). En dépit des progrès considérables réalisés dans le domaine de la dosimétrie des neutrons, il n'y a pas encore aujourd'hui de dosimètre susceptible de mesurer la dose due aux neutrons avec une précision acceptable quel que soit le spectre en énergie. Cet article présente les grandeurs dosimétriques utilisées en radioprotection. Il traite également des méthodes et des procédures d'étalonnages adaptées à la détermination de la dose aux postes de travail avec les appareils actuels dont les performances sont limitées. Les propriétés de ces instruments, incluant les dosimètres de zone, les dosimètres individuels et les ensembles de spectrométrie, sont décrites et les améliorations nécessaires exposées. En conclusion, la situation actuelle requiert des recherches complémentaires pour le développement des techniques de dosimétrie et l'étude des postes de travail.

\footnotetext{
* Cet article fait partie d'une série d'articles de synthèse consacrés à la dosimétrie et qui sera publiée durant l'année 1996.

** Physikalisch-Technische Bundesanstalt, Bundesallee 100, D-38116 Braunschweig, Germany.

*** Institut de protection et de sûreté nucléaire, DPHD-SDOS,F-92265 Fontenay-aux-Roses Cedex, France.
} 


\section{Introduction}

Practically the neutron fields in the nature are due to high-energy cosmic rays and are of practical relevance only in high-flying ( $\geq 10 \mathrm{~km}$ ) air- or spacecraft. In addition, man-made neutron fields are found in the controlled areas of nuclear fission reactors, i.e. power plants and research reactors, of fusion experiments and experimental fusion power reactors, and of particle accelerators for medical and industrial applications as well as for basic research in nuclear, high-energy particle and condensed matter physics. Finally, neutron fields are found near transport casks and intermediate repositories of highly radioactive waste, for instance as a result of $(\alpha, n)$ nuclear reactions. Due to their high penetrability as uncharged particles, neutrons often account for a substantial fraction of the total dose behind radiation shielding.

In spite of the comparatively low number of exposed persons, large expenditure is required for a sound neutron dosimetry for radiation protection purposes. Complications arise from the complicated nuclear, i.e. nuclide-specific interaction with matter which includes the complex multi-resonance energydependent structure and the fact that neutrons with energies as low as a few meV are captured and produce high-energy gamma rays with energies of up to several $\mathrm{MeV}$. Neutron energies between some meV (in nuclear reactors) and some $100 \mathrm{MeV}$ (in aircraft and behind the biological shielding of high-energy accelerators) are therefore of practical relevance and cover an energy range of at least ten orders of magnitude in which appropriate dosimetric instrumentation is needed. Additional complications arise from the energy-dependent quality factors and radiation weighting factors which require additional spectral information that goes beyond the mere measurement of the absorbed dose. This can usually be obtained by means of neutron spectrometry and/or transport calculations (e.g. Monte Carlo techniques). Finally, neutron fields are inevitably mixed neutron-photon fields and therefore require the application of special dosimetric techniques.

The correct application of these special techniques alone - without regard to any further research or development - obviously requires a minimum standard of expertise to be maintained.

\section{Dose quantities and requirements on dosemeters}

\subsection{Operational dose quantities, conversion factors and calibration}

A detailed discussion of dose quantities can be found elsewhere [44-45, 74$75,81]$. Operational dose quantities used in radiation protection, such as the ambient dose equivalent $H^{*}(10)$ for area monitoring or the personal dose equivalent $H_{\mathrm{p}}(10)$ for individual monitoring [44] are based on the dose equivalent $(D E)$ :

$$
H=\int Q(L) D_{L} \mathrm{~d} L=Q D
$$


Figure 1 shows the quality factor $Q(L)$ according to ICRP 60 [5] and the dose distribution $D_{L}(L)$ in equation (1) as a function of the linear energy transfer $L$ for the example of the ambient dose equivalent $H^{*}(10)$. Generally, this quantity is not directly measurable, i.e. no primary standards are available for this quantity. Therefore, it is derived from the (measurable) neutron fluence and the calculated fluence-to-ambient dose equivalent conversion function given by:

$$
h^{*}(E)=H^{*}(10) / \Phi
$$

where $\Phi$ is the fluence of monoenergetic incident neutrons with energy $E$ in an expanded and aligned field (Fig. 2). The $D E$ response of an area monitor in such a field is defined as:

$$
R_{H^{*}}(E)=M / H^{*}(10)=R_{\Phi}(E) / h^{*}{ }_{\Phi}(E) \text { with } R_{\Phi}(E)=M / \Phi
$$

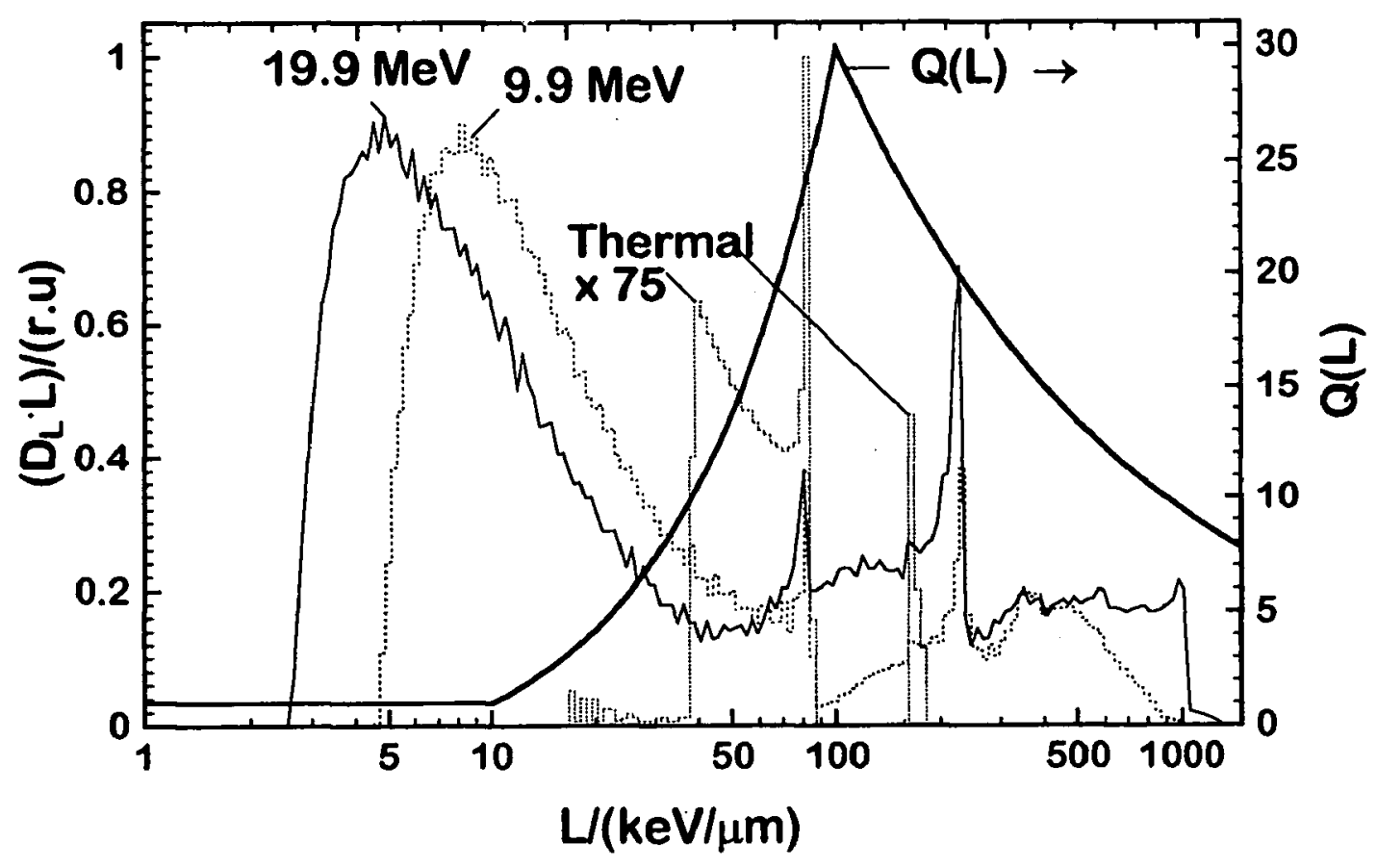

Fig. 1 - Plot of the functions $\mathrm{Q}(\mathrm{L})$ and $\mathrm{D}_{\mathrm{L}}$ of the integrand of equation (1) for the case of $H^{*}(10)$. In order to retain equal area mapping and considering the relation $\mathrm{D}_{\mathrm{L}} \mathrm{dL}=\mathrm{D}_{\mathrm{L}} \mathrm{L} d(\log \mathrm{L}), \mathrm{D}_{\mathrm{L}} \mathrm{L}$ is plotted as the ordinate for neutron energies of 19.9 and $9.9 \mathrm{MeV}$ and for thermal neutrons.

Représentation du facteur de qualité $\mathbf{Q}$ et de la distribution en dose $\mathrm{D}_{\mathbf{L}}$ en fonction du transfert linéique d'énergie (L) entrant dans le calcul de $\mathrm{H}^{*}(10)$ à partir de l'équation (1). En utilisant la relation $\mathrm{D}_{\mathrm{L}} \mathrm{dL}=\mathrm{D}_{\mathrm{L}} \mathrm{L} d(\log \mathrm{L})$, la fonction $\mathrm{D}_{\mathrm{L}} \mathrm{L}$ est portée en ordonnée pour les distributions en dose (pour les énergies de neutrons de 19,9 et de 9,9 MeV et pour les neutrons thermiques) afin d'obtenir des surfaces proportionnelles à la dose absorbée.

Here, $M$ is the reading of the monitor and $R_{\Phi}(E)$ the fluence response. If $R_{H^{*}}(E)$ is constant under all conditions, i.e. if $M$ is proportional to $H^{*}(10)$ independently of the neutron energy and direction of incidence, then the device is an ideal area dosemeter. Its fluence response $R_{\Phi}(E)$ should then be proportional to $h^{*}{ }_{\Phi}(E)$. In practice, however, such ideal dosemeters do not yet exist. 
Like the ambient dose equivalent the personal dose equivalent $H_{p}(10)$ is not directly measurable and therefore also derived from the neutron fluence and the calculated fluence-to-dose conversion function $h_{\mathrm{p} \Phi}=H_{\mathrm{p}}(10) / \Phi$ which, in this case, depends on the incident neutron energy and flight direction $\alpha$ in relation to the normal of the phantom front surface. The energy and directiondependent $D E$ response of an individual monitor is, in analogy to equation 3 , given by:

$$
R_{H_{\mathrm{p}}}(E, \alpha)=M / H_{\mathrm{p}}(10)=R_{\Phi}(E, \alpha) / h_{\mathrm{p} \Phi}(E, \alpha)
$$

In this equation, the reading $M$ of the individual monitor refers to a condition where the individual monitor is fixed on the front surface of the slab phantom so that here the responses depend not only on the energy but also on the direction $\alpha$. Figure 2 shows the neutron fluence-to-personal $D E$ conversion function $h_{\mathrm{p \Phi}}(E, \alpha)$.

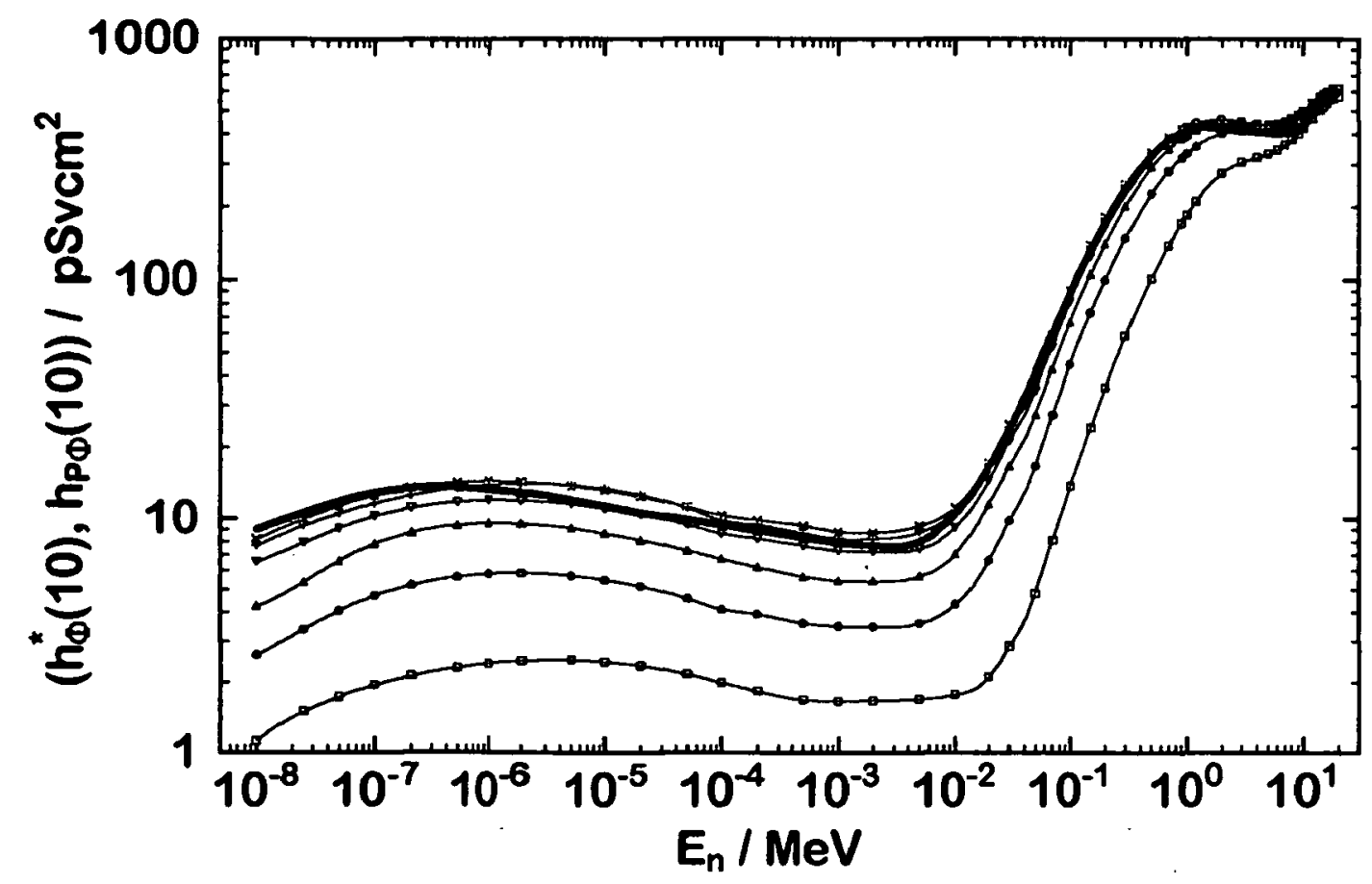

Fig. 2 - Fluence-to-ambient dose equivalent (thick line) and fluence-to-personal dose equivalent conversion factors as a function of incident neutron energy and (for the personal dose equivalent) of the angle of incidence, $\alpha$, with respect to the normal of the front surface, as calculated in [76]. From top to bottom: $\alpha=0,15,30,45$, 60 and $75^{\circ}$.

Coefficients de conversion de la fluence vers l'équivalent de dose ambiant (trait épais) et de la fluence vers l'équivalent de dose individuel en fonction de l'énergie des neutrons incidents et, pour l'équivalent de dose individuel, en fonction de l'angle d'incidence $(\alpha)$ par rapport à la normale à la face avant du fantôme [76]. $\left(\alpha=0,15,30,45,60\right.$ et $\left.75^{\circ}\right)$.

In a standard laboratory, the calibration, i.e. the determination of $R_{H}$ of area and personal dosemeters in terms of ICRU operational quantities requires 
the use of reference neutron radiations which are, among other quantities, characterised in terms of the spectral fluence, $\Phi_{\mathrm{E}}=\mathrm{d} \Phi / \mathrm{d} E$.

For the experimental investigation of the "unwanted" energy dependence of $R_{H}(E)$, monoenergetic neutron reference fields are of special interest. Considering the example of an area monitor, in a first step, $R_{\Phi}(E)$ is determined by measuring the readings $M$ and the corresponding fluence ( in various monoenergetic neutron fields, often at energies specified by an ISO standard [46]. In a second step, $h_{\Phi}^{*}$ is used to determine $R_{H}(E)$ according to equation (3).

Since the $D E$ responses $R_{H}$ of realistic neutron dosemeters turn out to be definitely energy-dependent, the dosemeters indicate the "true dose" only for the neutron spectrum in which they have been calibrated. Neutron reference fields whose spectra resemble the neutron spectra at workplaces have therefore received considerable interest (see Sect. 3). for example, the $D E$ response of an area monitor for such broad spectral distributions is given by the relations:

$$
R_{H^{*}}=M / H^{*}(10) \text { and } H^{*}(10)=\Phi \int h^{*}{ }_{\Phi}(E)\left[\Phi_{E} / \Phi\right] \mathrm{d} E
$$

In order to evaluate $R_{H^{*}}$, the reading $M$ and the corresponding fluence $\Phi=$ $\int \Phi_{E} \mathrm{~d} E$ have to be measured. In addition, the shape of the spectrum, $\Phi_{E} / \Phi$, must be known from measurements and/or calculations.

In general, it is necessary and by no means trivial to achieve calibration conditions at irradiation facilities which correspond to the definition of the quantities, e.g. well-known spectral and directional distributions, and the condition of an expanded and aligned field.

There is a strong need for a link between the computational approach of dosimetric concepts and their application in the laboratory. This is achieved by the set of ISO standards [46-47] dealing with reference neutron radiations for radiation protection dosimetry. In particular, they give guidance on several complementary topics such as the characteristics of reference radiations and the methods of their production, the physical quantities and specifications of the radiation fields including appropriate conversion factors. Procedures and calibration phantoms for personal dosemeter calibrations are recommended. Furthermore, they include recommendations which ensure that the calibration factor is a unique property of an instrument, implying the corrections of its reading for extraneous effects and corrections for unwanted contributions of background radiation before the appropriate fluence-to-dose equivalent conversion factors are applied. In addition, the uncertainties involved in the successive steps of the calibration procedures are considered and numerically estimated.

\subsection{Practical measurements in general neutron fields}

In general, the calibration on the basis of equation (5) is only valid for the neutron spectrum specified in this equation. This conclusion is arrived at if one 
looks, for example, at a personal dosemeter (reading $M$, on the phantom) in an expanded but otherwise general neutron field with a directional and spectral fluence distribution given by:

$$
\Phi_{E \Omega}=\mathrm{d}^{2} \Phi /(\mathrm{d} E \mathrm{~d} \Omega)
$$

where $\Omega$ indicates the flight direction of the incident neutrons. The reading is:

$$
M=\iint R_{\Phi}(E, \Omega) \cdot \Phi_{E \Omega} \mathrm{d} E \mathrm{~d} \Omega
$$

whereas:

$$
H_{\mathrm{p}}(10)=\iint h_{\mathrm{p} \Phi}(E, \Omega) \cdot \Phi_{E \Omega} \mathrm{d} E \mathrm{~d} \Omega
$$

Equations $(7,8)$ show that $R_{H_{\mathrm{p}}}=M / H_{\mathrm{p}}(10)$ generally depends on $\Phi_{E \Omega}$, unless $R_{\Phi}(E, \Omega)$ is proportional to $h_{\mathrm{p} \Phi}(e, \Omega)$ for all energies and directions, i.e. unless one has what has been termed an "ideal dosemeter" (see Sect. 2.1). In fact, such a dosemeter would measure $H_{\mathrm{p}}(10)$ in any unknown neutron field. Presently, however, no neutron dosemeter can satisfy with sufficient accuracy the requirements on energy and angle dependence in general neutron fields. To improve the rather limited capabilities of realistic neutron dosemeters, two methods can be used.

One method is based on determining the spectral neutron fluence at a given working environment and calibrating the neutron monitors in an identical or at least quite similar field, as it has been discussed with equation 5 (see also Sect. 3). This method results in more or less complicated spectrum measurements and a periodic verification of the spectrum in the working environment is necessary.

The other method is based on the use of a combination of sensors, with different energies and angle dependences of their responses, worn on one or several locations on the body. A detailed discussion of this method has been given [77] and a short outline is given below.

As in equation (7) the reading of the $i$-th of $I$ sensors, $M^{i}$, is given by:

$$
M^{i}=\iint R_{\Phi}{ }^{i}(E, \Omega) \Phi_{E \Omega} \mathrm{d} E \mathrm{~d} \Omega
$$

The basic idea of this method is to simply combine the $I$ sensors such that:

$$
h_{\mathrm{p}_{\Phi}}(E, \Omega)=\sum_{i=1}^{\mathrm{I}} u_{i} R_{\Phi}^{i}(E, \Omega)
$$

The $u_{i}$ are constants which can be arbitrarily fitted in order to satisfy equation (10). If such a set of coefficients $u_{i}$ can be found, then it follows from equations $(8,9)$ that:

$$
H_{\mathrm{p}}(10)=\sum_{i=1}^{\mathrm{I}} u_{i} M^{i}
$$


for general neutron fields, i.e. $H_{\mathrm{p}}(10)$ is obtained from a linear combination of the sensor readings. The $u_{i}$ may be considered as a set of generalized calibration constants.

Furthermore, by the combination of monitors worn on the chest and the back, the usual deficiency of single monitors (i.e. they are almost "blind" if radiation is incident on the back) can be remedied [48]. Analogous but even simpler considerations can obviously be made for area monitors for which only the energy dependence needs to be taken into account, because they should have an isotropic response.

\subsection{Mixed neutron-photon fields}

A two-sensor system is sometimes used for dosimetry in mixed neutronphoton fields. Usually a predominantly neutron-sensitive monitor ("rem counter"; 6LiF-TL-sensor) is combined with a predominantly photon-sensitive one (GM counter; ${ }^{7}$ LiF-TL-sensor). The readings of these two sensors or instruments can be written as a set of the two following equations $(i=1,2)$ :

$$
M^{i}=\left(R_{H_{\mathrm{n}}}\right)^{i} H_{\mathrm{n}}+\left(R_{H}\right)^{i \cdot H_{\gamma}}
$$

Provided the four $D E$ responses $R^{i}$ are known, this system of equations can be solved with respect to the neutron and photon doses $H_{\mathrm{n}}$ and $H_{\gamma}$. For this purpose, neutron responses of photon dosemeters have been measured for ionization chambers [40] and Geiger-Müller counters [51]. Another method uses the spectrometric properties of tissue-equivalent proportional counters, (see Sect. 4).

\section{Neutron spectra in working environments}

\subsection{Neutron spectrometers}

Neutron fields are fully specified by the direction-dependent spectral neutron fluence $\Phi_{\mathrm{E} \Omega}$. Any desired dose equivalent quantity $H$ can then be calculated by the generalized equation (8), i.e.:

$$
H=\iint h_{\Phi}(E, \Omega) \Phi_{E \Omega} \mathrm{d} E \mathrm{~d} \Omega
$$

using the corresponding fluence-to-dose equivalent conversion factors $h_{\Phi}(E$, $\Omega)$. A (trans)portable neutron spectrometer which has a reasonable angular resolution can, however, hardly be realized because massive neutron collimators would be required. Neutron spectrometers for use in radiation protection practice are therefore generally designed so that their fluence response is independent of the direction of incidence. The measured spectral neutron fluence can therefore only be used to derive a quantity such as the ambient dose equivalent. 
The result of a spectrometric measurement is generally a set of readings $M^{i}$ from a number of I different sensors $(i=1,2, \ldots, \mathrm{I})$, similar to equations (9):

$$
M^{i}=\sum_{j} R_{\Phi}^{i}\left(E_{j}\right) \Phi_{E_{j}} \Delta E_{j}
$$

where the fluence response matrix $R_{\Phi}{ }^{i}\left(E_{j}\right)$ has been determined by calculations and/or calibration measurements. The desired neutron spectrum $\Phi_{E_{j}}$, divided into energy intervals $\Delta E_{j}$, is then derived by unfolding equation (14). In addition to the requirement of a well-known response matrix, $R_{\Phi}{ }^{i}\left(E_{j}\right)$, further requirements on a neutron spectrometer are: the capability to discriminate photons and to cover a wide energy range from thermal to at least $20 \mathrm{MeV}$. Bonner sphere (BSS) and proton recoil (PRS) spectrometers are best suited for this purpose as was been demonstrated more than 20 years ago $[25,29,50]$. Since then considerable progress has been achieved in determining the response functions and analysing the measured data.

A BSS consists of a set of $I$ moderating spheres with a central thermal neutron detector, each furnishing a reading $M^{i}$. The central detector may be either an active detector, e.g. an LiI-scintillator, a $\mathrm{BF}_{3}$ - or ${ }^{3} \mathrm{He}$-filled proportional counter or a passive insert such as an Au-activation foil or a TLD chip. The diameters of the polyethylene spheres generally used range from $5.08 \mathrm{~cm}$ (2") to $45.72 \mathrm{~cm}\left(18^{\prime \prime}\right)$. The response matrix can be determined by experimental calibration [5] and Monte Carlo simulation [58, 82]. Various least-squares algorithms such as SAND [57], STAY'SL [63] or MIEKE [59] may be used to unfold the spectral neutron fluence from about 5 to 15 measured data. A resolution of 5 energy bins per one order of magnitude is desired over the whole energy range of up to at least 9 orders of magnitude. However, since the system of equation (14) is highly underdetermined, some a priori information is required in order to select the physically adequate solutions. But even if several possible solutions are taken into account, the derived integral quantities, i.e. neutron fluence and ambient dose equivalent, do not scatter by more than $10 \%$ and $15 \%$, respectively [6].

The requirement of a better energy resolution is most important in the energy range between $10 \mathrm{keV}$ and $1 \mathrm{MeV}$, where the fluence-to-dose equivalent conversion factors increase rapidly (Fig. 2). If this energy range notably contributes to the total dose, a PRS should be used in addition to improve the energy resolution. Here, the $I$ channels of the pulse height spectrum can be regarded as the readings $M^{i}$. When spherical or cylindrical proportional counters filled with hydrogen or methane gas at various pressures are used, the spectral neutron fluence can be determined with excellent energy resolution in an energy range from $10-50 \mathrm{keV}$ to $2-5 \mathrm{MeV}$ [31]. The range of low energy limits can only be realized if photon-induced events are discriminated by means of pulse shape analysis [19], while the higher-energy limit requires rather large volume detectors filled with a mixture of hydrogen or methane and range- 
reducing inert gases, such as Ar or Kr. The fluence response matrix can be calculated taking wall and electrostatic effects into account [80].

When neutrons with energies higher than $2 \mathrm{MeV}$ are present, an organic scintillation detector, for instance NE 213, should be used to complement the PRS. Since neutrons are generally encountered in mixed fields, neutron and photon-induced events must be separated by pulse shape analysis. The fluence response matrix for neutrons and photons can be calculated with high accuracy if the light output functions for secondary charged particles and the pulse height resolution function have iteratively been determined [41]. Instead of an organic scintillator, a ${ }^{4} \mathrm{He}$ filled proportional counter can be used in order to take high energy neutrons into account [20].

In the case of pulse height spectra, least-squares algorithms similar to those for few-channel unfolding are applied in order to evaluate the spectral neutron fluence from the measured pulse height spectrum. The results are unique since the fluence response matrices are generally well conditioned.

Figure 3 shows spectrum measurements in front of safes with $\mathrm{PuO}_{2}$ samples using BSS, PRS and an NE 213 scintillation detector [52]. Figure 3a shows a set of equivalent solutions from the BSS measurements. The superior energy resolution of the PRS and the NE 213 is demonstrated in Figure $3 \mathrm{~b}$. The peak structure of the spectral fluence evaluated reflects the $(\alpha, n)$ reactions on the oxygen of the sample and the resonance absorption of the shielding influencing the fission-like spectrum. The smooth spectrum obtained with the BSS (Fig. 3a) yielded, however, the same integral fluence and ambient dose equivalent for energies higher than $50 \mathrm{keV}$ and, in addition, accounted for the non-negligible contribution of thermal and intermediate-energy neutrons.

\subsection{Measurements in working environments}

Recently, neutron spectrometers have increasingly been applied to determine the spectral fluences at working places, e.g. in nuclear power plants [21], in fuel (re)processing plants [18], and in the environment of transport containers for spent fuel elements [68]. A great variety of neutron spectra has been encountered ranging from the original "hard" fission neutron spectrum to almost completely moderated "soft" spectra consisting of a thermal part and a $1 / E$ distribution ending with some hundred keV neutrons [12]. Neutron spectra recently measured with well-specified spectrometers have been compiled in a catalogue which also contains all relevant dose-to-fluence conversion functions and the response functions of personal and area dosemeters [78]. A versatile handling program allows fluence-averaged conversion factors to be calculated to characterize the hardness of the spectrum and to compare the expected reading of a monitor with the true dose quantity. From these investigations it became obvious that field-dependent calibration factors should be applied in most of the monitors used in radiation protection practice. 
$a$

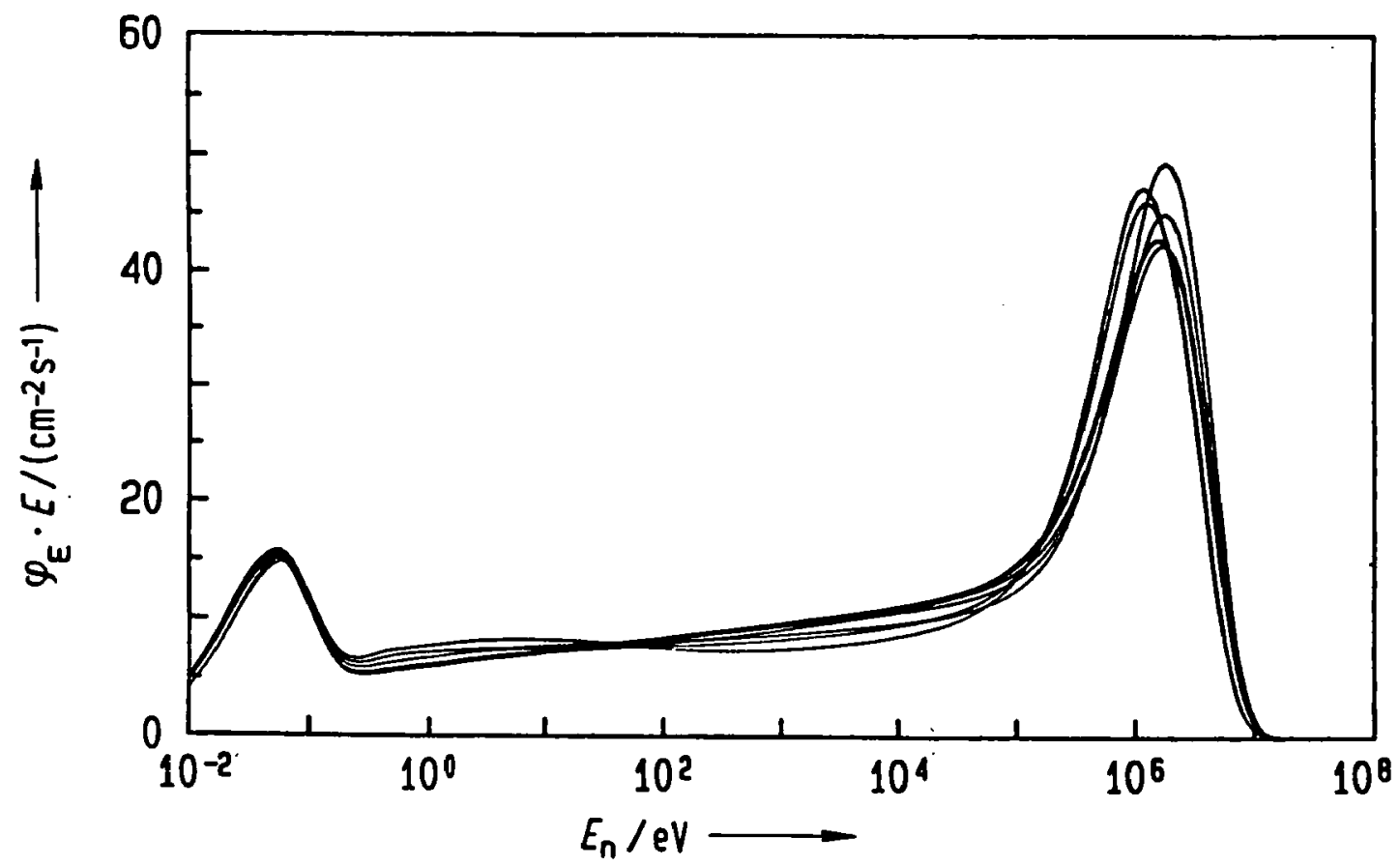

$\boldsymbol{b}$

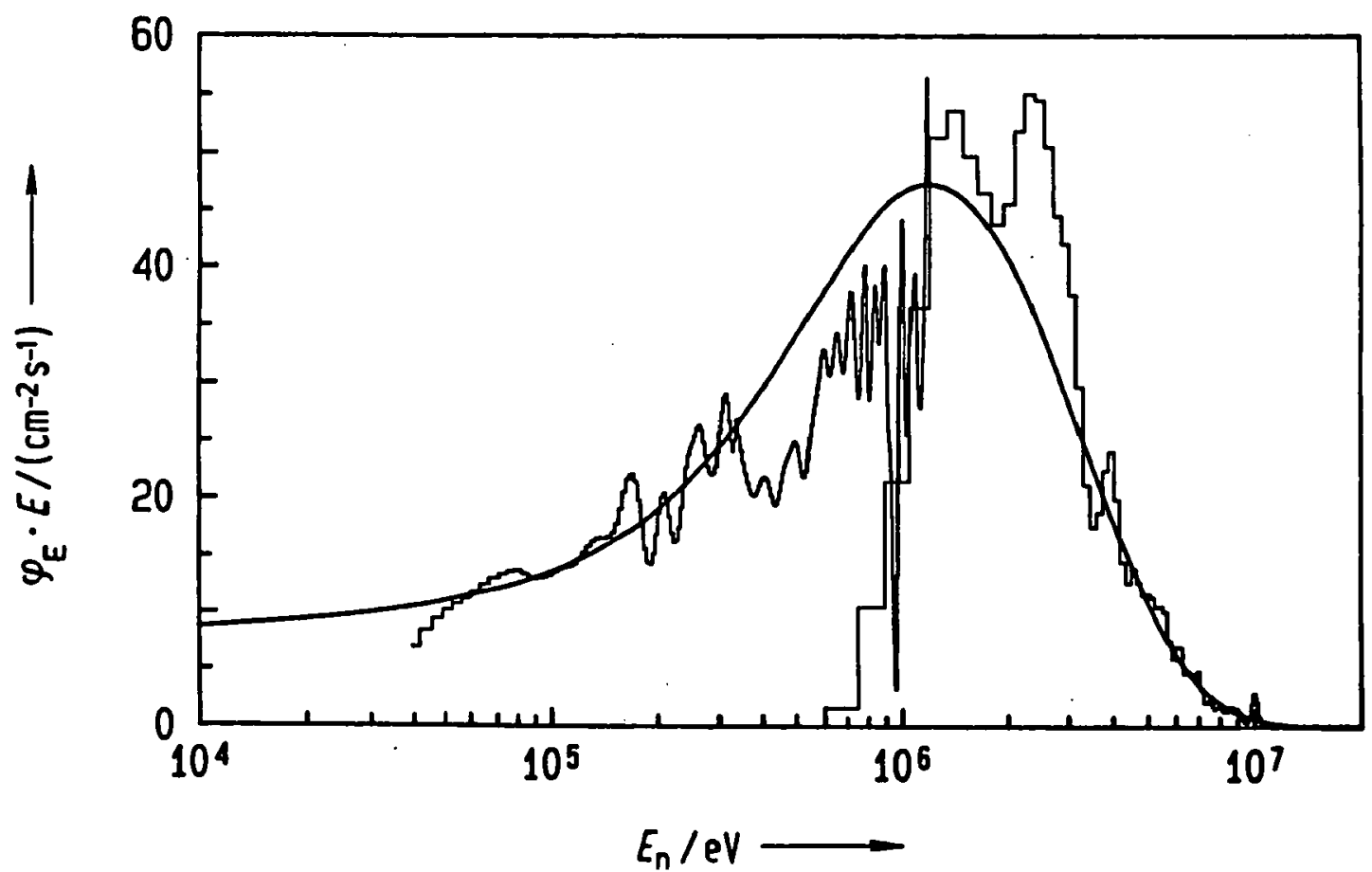

Fig. 3 - Spectral neutron fluence rate (in a "lethargy representation", see Fig. 1) encountered in front of safes with $\mathrm{PuO}_{2}$ samples: a) as measured with a Bonner sphere spectrometer (BSS); b) comparison of a selected BSS result with the partial spectra obtained with a liquid scintillation detector (NE213) and hydrogen-filled proportional counters $(P C)$ in the overlapping energy region (from [52]).

Débit de fluence de spectres neutrons (représentation en "léthargie", cf. Fig. 1) rencontrés auprès de châteaux contenant des échantillons de $\mathrm{PuO}_{2}:$ a) mesuré avec la méthode des sphères de Bonner (BSS) ; b) comparaison entre un des résultats précédents (BSS) et les spectres obtenus avec un scintillateur liquide (NE213) et des compteurs proportionnels remplis d'hydrogène $(P C)$ pour la gamme dénergie commune [52]. 


\subsection{Realistic neutron calibration fields}

Since reliable spectrometry requires much effort and is seriously hampered, for example, by extreme environmental conditions such as high temperature and humidity, acoustic noise and electromagnetic interferences and safety regulations in nuclear power plants, field calibrations cannot always be carried out. Neutron spectra typically encountered in practice are therefore simulated in calibration laboratories. Calibration is carried out using equation (5). On the basis of a ${ }^{252} \mathrm{Cf}$ source, either a pure fission spectrum or a $\mathrm{D}_{2} \mathrm{O}$-moderated spectrum can be realized according to ISO recommendations [46]. If such measurements are carried out behind shadow objects, the scattered background neutrons also form realistic calibration fields [7].

Appropriate calibration fields can also be realized with moderating assemblies surrounding an accelerator-based neutron source as demonstrated at the $14 \mathrm{MeV}$ neutron generator of IPSN/CEA in Cadarache. Monte-Carlo simulations of the neutron leakage spectrum were used to optimize the configuration [30] and, later on, these simulations were fully confirmed by spectrometry [68] (Fig. 4). These fields were successfully used for comparison exercises with different kinds of spectrometers, TEPC's and dosemeters performed under the auspices of the European radiation dosimetry group EURADOS.

\subsection{Limitations of neutron spectrometers}

While the uncertainty level of neutron spectrometry in the energy range below $20 \mathrm{MeV}$ seems to be acceptable for radiation protection practice, and even commercial neutron spectrometers are available in this energy range $[11,69]$, a problem remains to be solved in the spectrometry of neutrons with energies up to several hundred $\mathrm{MeV}$. These are encountered behind massive concrete and/or iron shielding of high-energy accelerators and in aircrafts flying at altitudes of 10 to $15 \mathrm{~km}$.

The response of moderating spheres decreases when the neutron energy increases beyond $20 \mathrm{MeV}$, and the energy dependence is rather similar for commonly used spheres [13]. The spectral fluence of high-energy neutrons can, therefore, be determined only by means of a BSS if a priori reliable information is available, at least on the shape of the spectrum, e.g. by Monte Carlo simulations as provided for the high-energy calibration fields at CERN $[8,14]$, or if the BSS is extended by detectors with completely different fluence response functions. Examples are fission counters containing ${ }^{232} \mathrm{Th}$ and ${ }^{209} \mathrm{Bi}[14,33]$ or double-moderator assemblies with inner metal shells taking advantage of the energy dependence of $(n, x n)$ - reactions in order to increase the fluence response at high neutron energies [22]. Even organic scintillators $10 \mathrm{~cm}$ in length can only be applied for neutron energies smaller than about $100 \mathrm{MeV}$ due to the wall effects which strongly increase with the recoil proton energy [61]. The major drawback of all high-energy neutron detectors is, however, that the fluence response functions cannot be calculated as reliably as for neutron energies below $20 \mathrm{MeV}$ because the relevant cross sections are little known. For the same reason and because experimental methods are presently not yet satisfactorily developed, calibration fields cannot be easily specified [61]. 
$a$

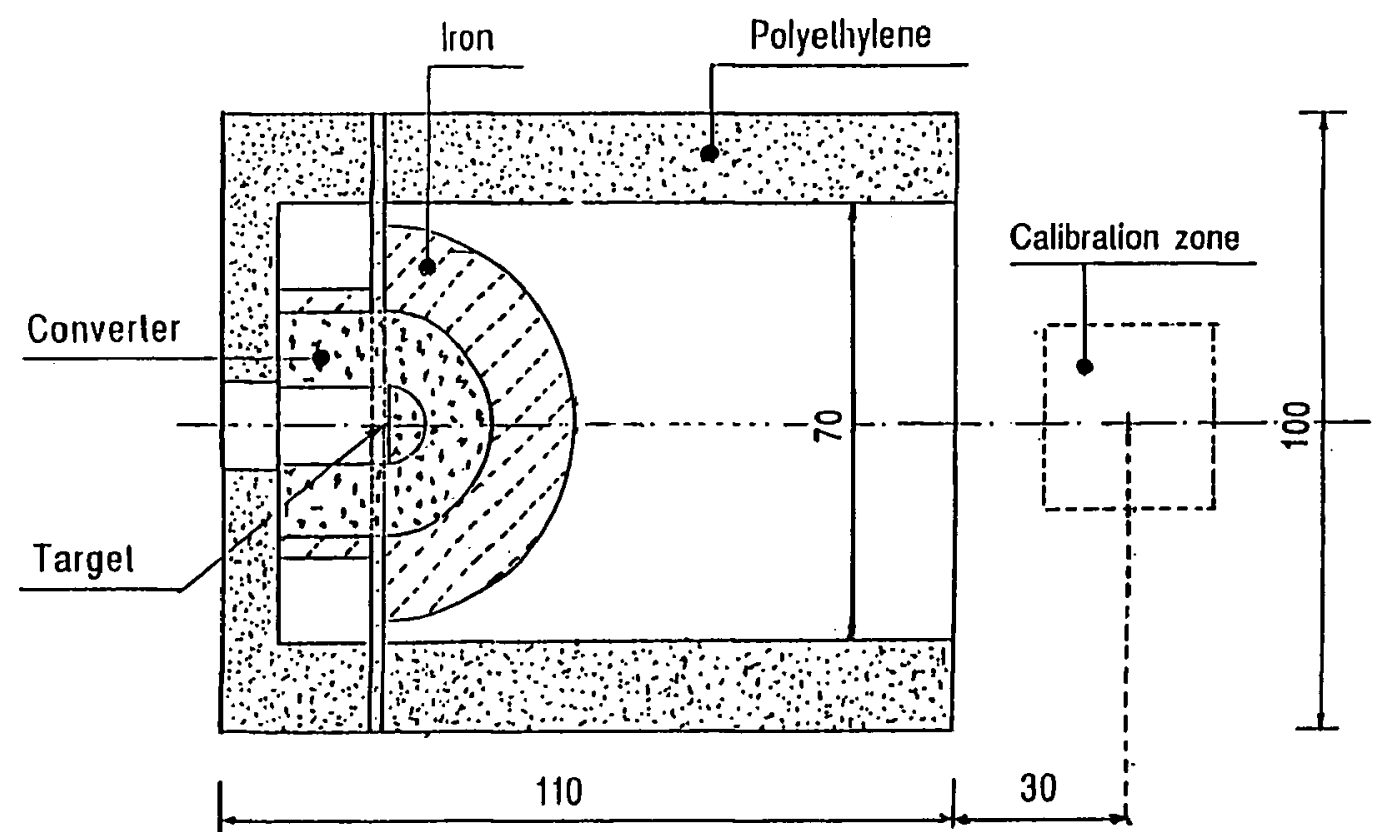

$\boldsymbol{b}$

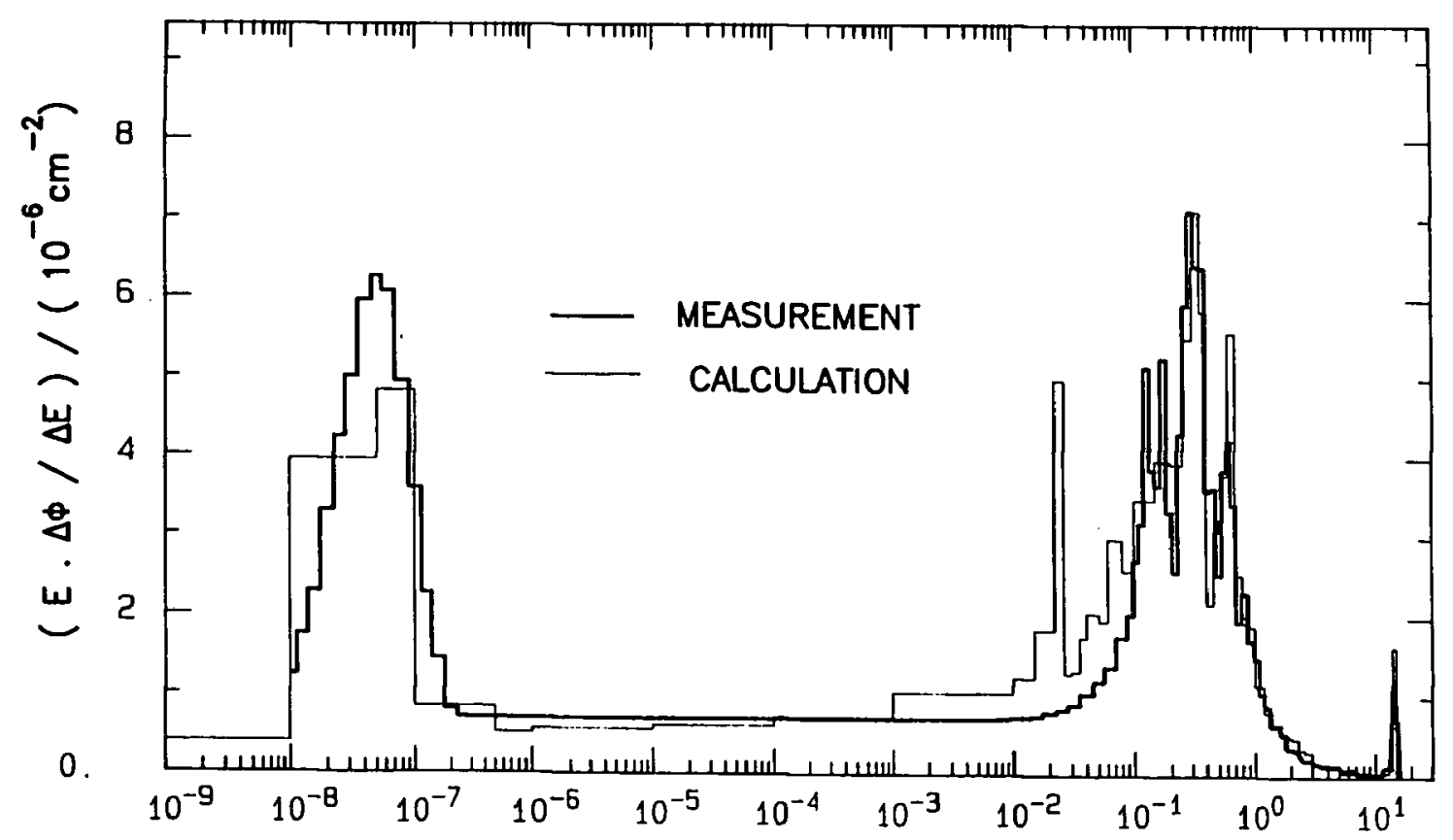

Neutron energy / MeV

Fig. 4 - A realistic neutron calibration field: a) moderator assembly at the 14 MeV generator of $C E A$ in Cadarache [30]; b) comparison of the spectral neutron fluence in the calibration zone as calculated with the MCNP code and measured with Bonner spheres, hydrogen-filled proportional counters and an NE213 scintillation detector (from [68]).

Spectre réaliste de neutrons pour l'étalonnage : a) assemblage modérateur placé devant une source de neutrons de $14 \mathrm{MeV}$ au CE Cadarache (IPSN-SDOS) [30] ; b) comparaison des spectres de fluence de neutrons dans la zone d'étalonnage calculé avec le code MCNP et mesuré avec les sphères de Bonner, les compteurs proportionnels remplis d'hydrogène et un scintillateur NE213 [68]. 


\section{Area monitoring}

\subsection{General}

Neutron area monitors are intended to measure the ambient dose equivalent, $H^{*}(10)$, particularly at workplaces, in order to characterise a workplace and to provide data for additional radiation protection measures (e.g. shielding), to define controlled areas, to survey such areas and, occasionally, to warn people if a certain level of ambient dose equivalent rate is exceeded. Most of the area monitors used for these purposes are active devices; only for long-term measurements, e.g. in the environment of nuclear installations, can passive methods be applied. Neutron monitors used in daily routine must be practical, economical, easy to read and to install and sensitive to low neutron dose equivalent rates.

\section{2 “Adjusted-fluence" meters}

Most active devices used in present practice are based on the moderator principle: a detector for slow neutrons (e.g. a ${ }^{3} \mathrm{He}$ or $\mathrm{BF}_{3}$ proportional counter or a ${ }^{6} \mathrm{LiI}$ scintillator) is surrounded by a hydrogenous moderating material (e.g. polyethylene) which is designed in such a way that the $D E$ response of the monitor to $H^{*}(10)$ is as independent of the neutron energy as possible. However, the classical rem counters (with cylindrical moderator according to Andersson and Braun [9] or with a spherical moderator according to Leake [53]) still show a relative overresponse at intermediate energies and a drop of the response above $10 \mathrm{MeV}$ (Fig. 5). Recent modifications of this type of rem counter aim at a better $D E$ response at higher energies [22] or at a less energydependent $D E$ response in the range below $1 \mathrm{MeV}$ [27].

The large energy dependence of the $D E$ response of devices based on one detector has led to the development of instruments with more than one detector with different moderators and thus different energy dependences. Typical examples of such developments are the "Dineutron" [60] with two relatively small spheres (diameters: $10.7 \mathrm{~cm}$ and $6.3 \mathrm{~cm}$ ) or the "single-sphere albedo technique" [28] which makes use of three ${ }^{3} \mathrm{He}$ counters at different positions in and on the same spherical polyethylene moderator. The rough spectrometric information gained from the readings of the two or three detectors can be used to reduce the energy dependence of a fitted $D E$ response in the energy range up to $20 \mathrm{MeV}$, resulting in an improved measurement of ambient dose equivalent in unknown neutron fields.

A different detection principle applicable in area monitoring, the superheated-drop detector, SDD, was recently investigated [32]. It is based on energy transfer to the superheated drops by charged particles. Like most of the moderator-type dosemeters described above, it is insensitive to photon radiation; the energy dependence of the DE response between the lower threshold of about $100 \mathrm{keV}$ and $15 \mathrm{MeV}$ is within a factor of two (Fig. 5). A similar response for thermal neutrons is achieved via the exoenergetic ${ }^{35} \mathrm{Cl}(\mathrm{n}, \mathrm{p}){ }^{35} \mathrm{~S}$ reaction in the drops themselves. 


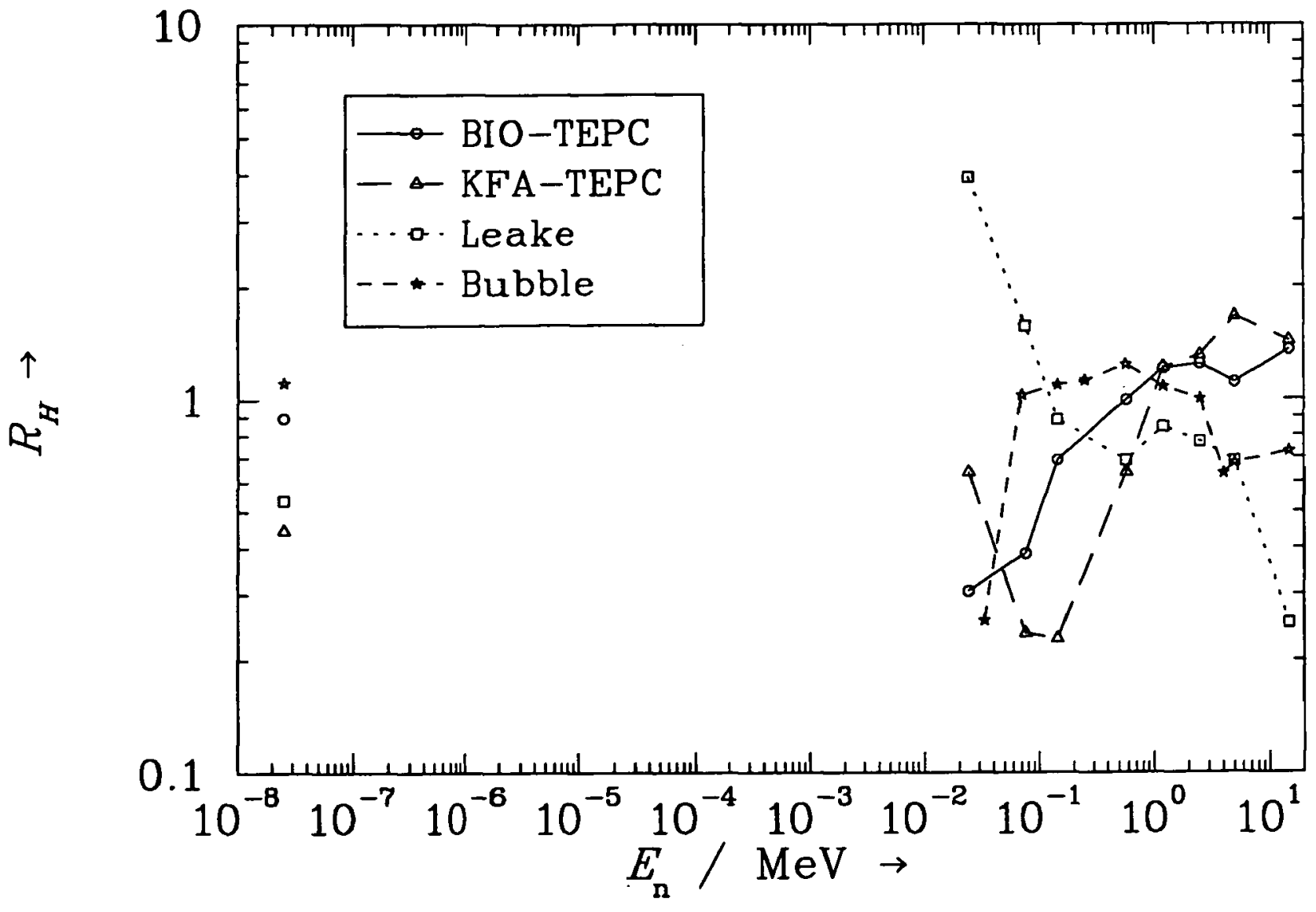

Fig. 5 - Dose equivalent response, $\mathbf{R}_{\mathrm{H}}$ for the new $\mathrm{H}^{*}(10)$ according to ICRP 60 [45, 74, 75] as a function of the neutron energy for a thin-walled (BIO) and a thickwalled TEPC area monitor (KFA), a rem counter (Leake) and an SDD. For TEPCs and rem counter the data represent re-evaluations [71] - for the new $\mathrm{H} *(10)$ and for a calibration in a $\mathrm{D}_{2} \mathrm{O}$-moderated ${ }^{252} \mathrm{Cf}$ field - of results from an intercomparison [1]. The SDD data [32] have been renormalized setting $\mathbf{R}_{\mathrm{H}}=1$ at $\mathrm{E}_{n}=2.5 \mathrm{MeV}$.

Réponse en équivalent de dose, $R_{H}$, pour la nouvelle valeur de la grandeur $H^{*}(10)(C I P R$ 60) (45, 74-75) en fonction de l'énergie des neutrons pour un CPET à paroie fine (BIO), un CPET a paroie épaisse (KFA), un rem mètre (Leake) et un détecteur à bulles type SDD. Pour les CPET et le rem mètre, les valeurs proviennent d'une réévaluation [71] des résultats d'une intercomparaison [1], basé sur un étalonnage au ${ }^{252} C f\left(D_{2} O\right)$. Les résultats du détecteur à bulles [32] ont été renormalisé à la valeur $\mathbf{R}_{\mathrm{H}}=1$ à $2,5 \mathrm{MeV}$.

\section{3 "Weighted-dose" meters}

All detectors described hitherto measure essentially a weighted neutron fluence with a response tailored to give a dose equivalent reading independent of energy. Two other types of detectors, the tissue-equivalent proportional counter (TEPC) developed as a byproduct of microdosimetric research and the recombination chamber ( $\mathrm{RC}$ ), work on totally different principles. They measure the absorbed dose in tissue-equivalent material and use additional measurement parameters to evaluate an average quality factor and, as a product of these quantities, the dose equivalent. 


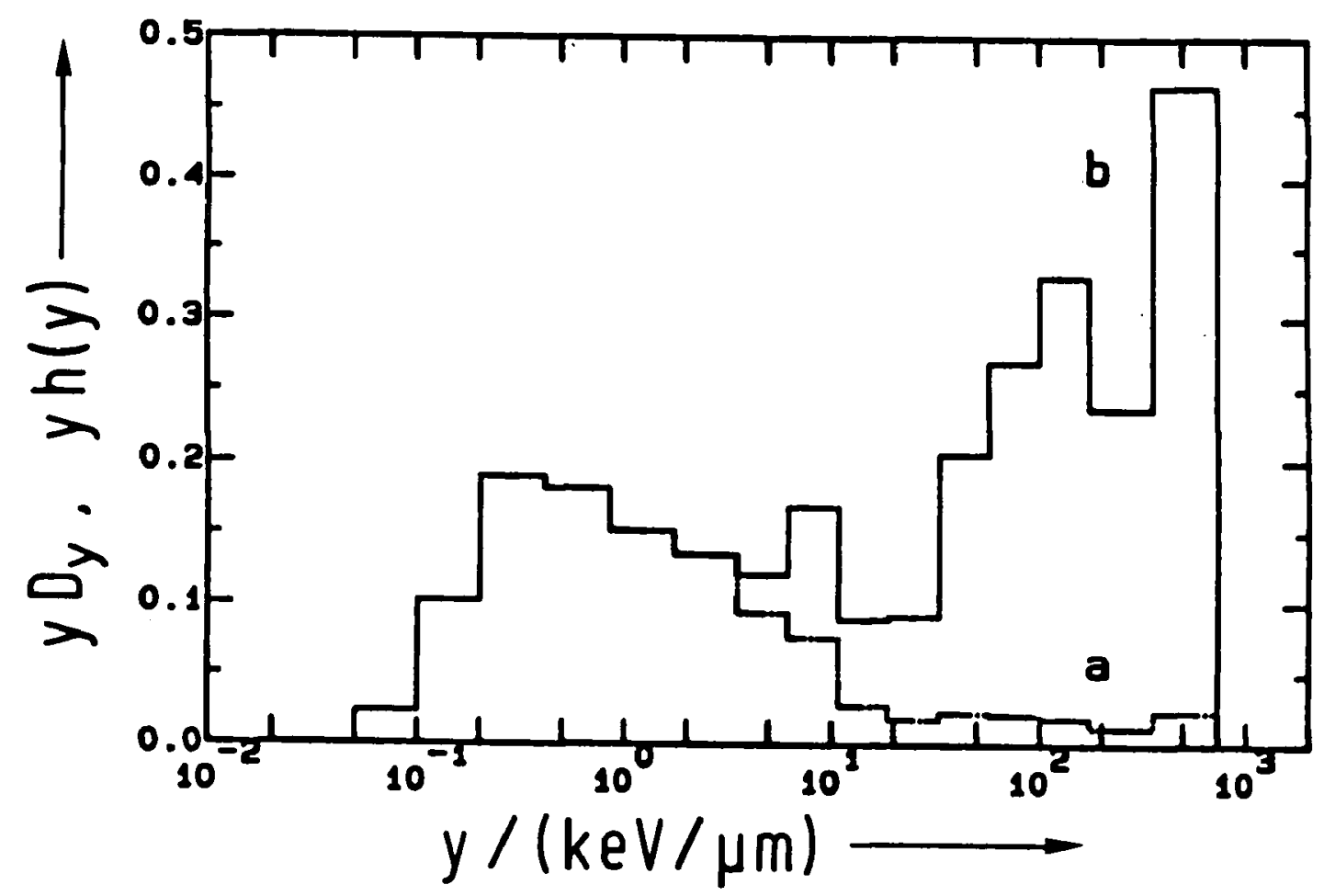

Fig. 6 - a) absorbed dose, $\mathrm{yD}_{\mathrm{y}}$ as a function of lineal energy, $\mathrm{y}$, measured with the HANDI TEPC-type area monitor on board of civil aircraft [73] in arbitrary units; b) dose equivalent, y.h(y), for the same measurement. In this representation (i.e. multiplication by y) equal areas under the curves correspond to equal values of absorbed dose or dose equivalent, see Fig. 1.

a) spectre microdosimétrique en dose absorbée, $\mathrm{yD}_{\mathrm{y}}$, en fonction de l'énergie linéale, y, mesurée avec le dosimètre de zone HANDI (dérivé d'un CPET) à bord d'avion civil [73] unités arbitraires) ; b) spectre microdosimétrique en équivalent de dose y.h(y) pour la même mesure que a). Pour ces tracés (c'est-à-dire en multipliant par y), la surface sous la courbe est proportionnelle à la dose absorbée ou l'équivalent de dose (cf. Fig. 1).

An overview of the status of TEPC area monitors was given recently [71]. The TEPC consists of a tissue-equivalent plastic material filled with a tissueequivalent counting gas at very low pressure. Charged particles (secondary particles produced in the detector wall or charged particles from the external primary field) crossing the sensitive volume can be measured as single ionization events. The frequency distribution of these events in relation to the "lineal energy" $y=\varepsilon / l$ ( $\varepsilon$ energy deposited in the volume, $l$ mean chord length of the volume) allows to derive a dose equivalent reading of the TEPC in analogy to equation (1) to be derived:

$$
H_{\mathrm{TEPC}}=\int q(y) D_{y} \mathrm{~d} y
$$

where $q(y)$ is an approximation of $Q(L)$ and $y$ is assumed to be a good approximation of the linear energy transfer $L$. Figure 6 shows typical spectra of $D_{y}$ and $h(y)=q(y) D_{y}$ measured on board of high-flying aircraft. Events with $y>10 \mathrm{keV} / \mu \mathrm{m}$ are mainly attributed to neutrons. Due to limits of the approximation $y \approx L$ and the different scattering properties of a TEPC as compared 
with the phantom used in the definition of $H^{*}(10)$, the $D E$ response is not independent of the energy (Fig. 5). This effect depends in detail on the TEPC geometry, the wall thickness in particular.

The RC is a high-pressure ionisation chamber operated in the non-saturated mode. In this mode a low collecting voltage allows the measured current to be influenced by the initial recombination of ions. This effect depends on the $L$ of a charged particle such that the quality factor $Q$ can be approximated by an empirical relation based on the ratio of the non-saturated to the saturated ion current [37].

Area monitors of the first category, i.e. the adjusted fluence meters, are sensitive to neutrons only, hence additional photon-sensitive detectors are needed in order to determine the total dose equivalent (see Sect. 2.3). Those of the second category, the dosemeters, are sensitive to all kinds of radiation, hence they measure the total dose equivalent. Within certain limits, the TEPC and the $\mathrm{RC}$ allow photon (low $L$ ) and neutron (high $L$ ) doses in mixed radiation fields to be separated.

\subsection{Comparison}

For the energy range for which experimental data are available (Fig. 5), the ratio of the maximum to the minimum of $R_{H}$ is 17 for the Leake rem counter, 5 for BIO, 7 for KFA and 5 for SDD. Results for the RC, evaluated for the old $H^{*}(10)$ (i.e. $Q(L)$ according to ICRP 26) and for similar energies, show a variation of up to a factor of 5 [37]. The fact that experimental data do not exist for the energy range between thermal neutrons and $10 \mathrm{keV}$ limits the conclusions with regard to the dosimetric properties in unknown radiation fields. The relevance of this statement is, however, limited by the fact that there are few workplaces with a large fraction of dose equivalent in this energy region. For neutron energies above $20 \mathrm{MeV}$, only few $R_{H}$ data are available, mainly because calibration fields for higher-energy neutrons have become available only recently [72]. For the TEPC systems, measurements of $R_{H}$ at $19 \mathrm{MeV}$ [73] and estimates of $R_{H}$ up to $60 \mathrm{MeV}$ [72] confirm the expected low energy dependence at higher energies.

The sensitivities of the various instruments are sufficiently high to measure a dose equivalent rate of $0.5 \mu \mathrm{Sv} / \mathrm{h}$ which has been proposed as a "minimum detection threshold" for an area monitor [66]. For the TEPCs, however, sensors with volumes larger than $300 \mathrm{~cm}^{3}$ are required [71].

Moderator-type instruments have proved to be rather robust, reproducible and easy to operate. They have been frequently used for many years, in particular at fission reactors. Except for the modified version [22], moderator-type area monitors are not suited for radiation fields which contain a significant fraction of neutrons with energies above $10 \mathrm{MeV}$, for example, at particle accelerators, in aircrafts and spacecrafts. The SSD and the RC have been employed 
in practice in a few radiation fields. TEPC area monitors should still be regarded as prototypes because many of their technical properties are yet unknown despite their well-known dosimetric properties. Many applications of TEPC systems, in particular as reference dosemeters in unknown radiation fields, have been reported in the past years (see references in [71]). They underline the need for dosemeters which allow additional information on the radiation field to be obtained (average quality factor, average photon and neutron energy) for the characterization of workplaces.

\section{Individual monitoring}

\subsection{General}

Routine individual monitoring of workers exposed to mixed neutronphoton radiation fields with a considerable dose contributed by neutrons requires personal neutron dosemeters. A personal dosemeter should ideally show a $D E$ response independent of neutron energy. Such a dosemeter has not been available up to now, but there are some new developments in this direction combining different detection techniques; they will be discussed below. The introduction by the ICRU of new operational quantities for individual monitoring (see [81] and Sect.2) for which the fluence-to-dose equivalent conversion factors vary also with the angular distribution of radiation incidence (Fig. 2), influences the design of personal dosemeters as well.

\subsection{Passive personal dosemeters}

For economical reasons, most personal neutron dosemeters used routinely are of the passive type. They are worn for a period of one to three months and should show no fading of the radiation-induced signal during this time. A reliable automatic read-out procedure should be available. Desirable is the possibility of repeated read-out and a large linear dose range to make a safe estimate possible in the case of an accident. All these requirements must be satisfied with small, light-weight and robust dosemeters.

The most important detection methods in routine use discussed below are nuclear photographic emulsions, thermoluminescence albedo detectors (TLD), etched-track detectors and, for special applications, bubble dosemeters [35-36, 38-39].

Nuclear emulsions can primarily detect recoil protons produced by neutron scattering by hydrogen contained in the emulsion and in the surrounding plastic material. The smallest detectable track length, given by 3 to 4 developed silver grains, corresponds to protons with $0.5 \mathrm{MeV}$ energy. Since neutrons with energies of $1 \mathrm{MeV}$ produce recoil protons with a mean energy of $0.5 \mathrm{MeV}$, the nuclear emulsion has a high energy threshold for neutrons at about 0.5 to $1 \mathrm{MeV}$. Such dosemeters are therefore not very useful at power reactor plants, 
where the main contribution to the dose is by neutrons with energies below $1 \mathrm{MeV}$. However, they are still useful near high-energy accelerators [23] after the technique has been improved [42]. The fading problem has been partly solved by sealing the films under dry nitrogen atmosphere in an aluminised plastic pouch. Fading has thus been reduced, but it is still as high as $20 \%$ for a usual wearing period of one month. Further problems arise with a fogging of the films by photon doses of some $\mathrm{mSv}$, which makes track counting impossible, and by protons of $0.6 \mathrm{MeV}$ produced by thermal neutrons via the ${ }^{14} \mathrm{~N}(\mathrm{n}, \mathrm{p})$ reaction. These problems can, however, be overcome by appropriately shielding the film with $\mathrm{Pb}$ and $\mathrm{Cd}$ layers. The tracks must be counted visually using a microscope; the lower dose limit lies at $0.4 \mathrm{mSv}$.

Thermoluminescence detector materials detect thermal and epithermal neutrons in most cases via the ${ }^{6} \mathrm{Li}(\mathrm{n}, \alpha)$-reaction. Intermediate and fast neutrons are detected in neutron dosemeters by measuring the thermalized neutrons backscattered from the body, i.e. albedo neutrons. Since the albedo $D E$ response decreases by two orders of magnitude in the neutron energy region between $10 \mathrm{keV}$ and some $\mathrm{MeV}$, the dosemeters must, in principle, be calibrated in the radiation field where they are used. In the various neutron fields of practical relevance in radiation surveillance, calibration factors differing by a factor of 25 (!) must be used [64]. In order to obtain a "field calibration", additional spectral information is utilized such as the ratio of the readings of two Bonner spheres (with diameters of, for example, 7.6 and $22.9 \mathrm{~cm}$, the 3"/9" ratio) or by relating the readings of two opposite albedo dosemeters on a $30 \mathrm{~cm}$ diameter sphere to the "rem-counter" reading measured by TLD chips in the center of the same sphere. TLDs are also sensitive to photon irradiation. This contribution can be subtracted by a TLD detector which is only photon sensitive (in most cases TLD material with ${ }^{7} \mathrm{Li}$ only). However, in fields with high-energy neutrons, where the reading due to neutrons is low, this subtraction procedure can result in large uncertainties. The lower dose limit depends on the working area in which the dosemeter is worn and can be as low as $0.02 \mathrm{mSv}$ in fields with chiefly thermal and intermediate neutrons. Automatic TLD readers make a fast and cheap evaluation possible. The main problem with TLD albedo dosemeters is the determination of the correct calibration factor. In Germany, where one of the most advanced TLD-systems is used [64], four different application areas are defined, in each one the calibration factor still varies by a factor 2 to 3 . This variation can be reduced either by determining the spectrum (Sect.3) or, particularly in areas with high energy neutrons, by using as an additional spectral information a relation which has been found to be the ratio of the readings of the albedo detector and an additional sensor for thermal neutrons from the external field.

Among etched-track detectors, the plastic CR-39 has gained in importance in neutron dosimetry. It can detect protons with energies as low as $50 \mathrm{keV}$ and is photon-insensitive. The $D E$ response depends on the etching techniques used and the hydrogen-containing radiators in front of the detector. Both the energy and angle dependence of CR-39 etched-track detectors have been 
investigated in several EURADOS-CENDOS experiments (see for example [2]). For normally incident neutrons $D E$ response functions have been achieved which are constant within a factor of 2 in the neutron energy range from $144 \mathrm{keV}$ to $15 \mathrm{MeV}$. The angle dependence of the response of CR-39 dosemeters is, however, stronger than that of the personal dose equivalent $H_{\mathrm{p}}(10)$ (see Fig. 2), especially for neutron energies between about 100 and $200 \mathrm{keV}$. The use of cylindrically shaped track detectors or a detector system of several CR39 pieces mounted on wedges can, in principle, solve this problem, but issuing and evaluating of these systems may be too much time-consuming. The low energy threshold at about $100 \mathrm{keV}$ neutron energy makes it possible to use CR-39 dosemeters at workplaces with appreciable doses of high-energy neutrons and near reactors. In reactors, however, slow neutrons (thermal to $0.5 \mathrm{eV}$ ) may contribute between $2 \%$ and $61 \%$ to the dose [12, 67]. The interpretation of dosemeter readings therefore requires additional information on the working environment. Although CR-39 dosemeters have been introduced in routine surveillance in several countries, their advantage is questioned by others [2] because of high background variations. A low dose limit of 0.1 to $0.2 \mathrm{mSv}$ can be achieved [2-3]. Higher values as a result of a fluctuation of the CR-39 track background are possibly due to $\alpha$-particles emitted from radon and its daughter products. A careful handling using radon-tightly packed CR39 detectors is therefore necessary [3].

Bubble or superheated drop dosemeters have been given increasing attention as they are very sensitive to neutrons, insensitive to photons and allow immediate read-out. They can be evaluated, for example, visually by counting the bubbles fixed in the gel [43] or by measuring the vapour volume [10]. The lower energy threshold can be varied in the neutron energy range of interest, from $10 \mathrm{keV}$ to $10 \mathrm{MeV}$ [65], by using different materials. Despite their sensitivity to neutrons (lower dose limit: $0.05 \mathrm{mSv}$ ), the sensitivity to temperature and shock impedes their being introduced into individual routine monitoring. They may be useful, however, as an additional "active" dosemeters for limited periods of time and special applications.

Considerable improvements of the energy dependence of the $D E$ response may be expected when more than one detector is used (Sect. 2, Eqs 9-11). A track detector/TLD albedo combination dosemeter has been proposed [54] whose $D E$ response is almost flat except for an overresponse in the intermediate energy region. This is acceptable since this energy region contributes only a few percent to the dose equivalent at most workplaces. Another combination dosemeter which has been proposed recently consists of TLDs with two bubble detectors (with different thresholds at $100 \mathrm{keV}$ and $1.5 \mathrm{MeV}$ ) [26].

An approach using a single detection technique combined with different converter and/or radiator foils is based on a CR-39 detector [55,62, 79]. The $D E$ response of one of the most recent designs inserted into an albedo capsule is shown in Figure 7 [56]. Three different parts of the CR-39 track detector are covered by different converters, two of which are boron-loaded. Using a posi- 
tion-related read-out of the track densities after electro-chemical etching and applying simple arithmetic procedures, a "spectrometer" has been designed which separately indicates dose equivalents due to thermal, intermediate and fast neutrons. It still shows some energy dependence within each energy group and an angle dependence of the response similar to that of other types. Its advantage, however, is the increased spectral information which allows arithmetic optimisation of the response according to the fluence-to-dose equivalent conversion functions actually prevailing. Further, exceptional exposures due to unwanted radon background can be reanalyzed by a second dose reading procedure [56].

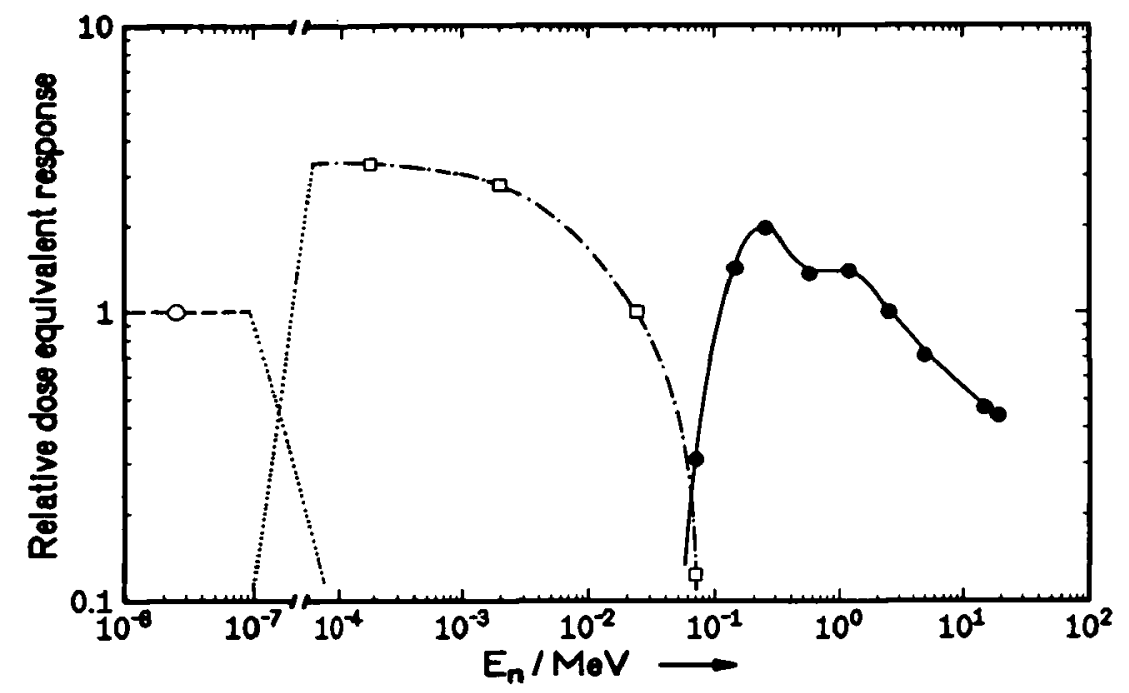

Fig. 7 - Measured dose-equivalent response of a neutron individual dosemeter/spectrometer based on a single CR-39 track detector [56]. The responses have been normalised to unity for thermal, $24 \mathrm{keV}$ and $2.5 \mathrm{MeV}$ neutrons.

Réponse en équivalent de dose mesurée avec un dosimètre-spectromètre individuel utilisant un seul détecteur solide de traces de type CR39 [56]. Les résponses ont été normalisées à l'unité pour les neutrons thermiques ainsi que pour les neutrons de $24 \mathrm{keV}$ et de 2,5 MeV.

\subsection{Active personal dosemeters}

All the dosemeters referred to above are passive detectors (except, to a certain extent, super-heated drop detectors). Work in controlled areas at elevated dose rate levels shows the necessity of carrying out real time measurements to warn people when a certain level of personal dose equivalent is exceeded. Electronic devices will be able to fulfill this requirement.

Beside a few more investigations in the field of electronic dosemeters, which pursued different courses and cannot be referred to here, the methods presented below seem to be the most promising ones for the nineties to speed up personal dosimetry. 
Many devices based on silicon diodes have been extensively described. Such neutron-sensitive instruments contain two detectors to correct for the sensitivity to photons or for the lack of sensitivity for neutron energies under $500 \mathrm{keV}$. Roughly speaking, two methods are applied. In the first one [15], a silicon diode covered with a boron-loaded polyethylene converter measures neutrons and photons, whereas the second silicon diode is bare and measures only photons. Neutron information is derived from the difference between the two diode signals. This method needs two identical silicon diodes which are not easily available. This dosemeter has a low sensitivity for low-energy neutrons and a high sensitivity for photons. The lower energy threshold of such dosemeters for fast neutrons in realistic conditions is estimated to be about $500 \mathrm{keV}$ [16]. An attempt has been done to optimise the first method by using two diodes located on the opposite side on the same silicon substrate, but the results obtained are quite the same as with two separated diodes [34]. This example shows the interdependence of microelectronics and dosimetric investigations. However, in any case, the cost of commercial dosemeters is an important parameter to be kept in mind. In the second method, the first diode, covering the range of thermal and low-energy neutron, consists of a ${ }^{10} \mathrm{~B}$ silicon junction with polyethylene converter and moderator while the other silicon diode is meant to detect fast neutrons and is covered only by a polyethylene radiator. An electronic threshold on the pulse height suppresses the photon pulses. There are two features inherent to this second method: a dip in sensitivity at neutron energies around $1 \mathrm{MeV}$ and an increase for low-energy neutons around few keV [4]. The dose equivalent responses are given in Table I.

The deficiencies of two-diode systems can be corrected, at least partially, by using a single silicon diode covered with a boron-loaded polypropylene radiator and carrying out a rise time pulse analysis [17]. Photon-to-neutron discrimination is based on a rise time pulse rejection threshold (Fig. 8). This type of dosemeter is able to combine fast neutron and albedo dosemeter characteristics through sensitivity to thermal and fast neutrons. At this stage of the studies, photon rejection and neutron sensitivity need a compromise solution. As hydrogenous converters are used, the angle dependence of the response of diode dosemeters is close to that of etched-track detectors with plane geometry.

Using a static random access memory, Schröder [70] measured $L$-distributions resulting from mixed (neutron-photon) fields. The voltage across the diode generates a funneling effect because the electrons move faster than the holes. The $L$-spectra from neutrons show a shape comparable to that of spectra measured with TEPCs. The difference in pulse height distributions which are generated by neutrons and photons should allow electronic discrimination between them. The problems arise from large angles of incidence causing the device to measure the total energy of the particle rather than simply $L$, and from the difference in composition between tissue and silicon.

Kadachi [49] processes the pulse-height spectra obtained by a PIN photodiode detector with a computer code. The detector is covered with a $2 \mathrm{~mm}$ 
thick hydrogenous converter to determine the microdosimetric spectra. Microdosimetric distributions for photons are almost similar to those obtained with TEPCs, but a marked difference in shape is found in the case of mixed fields. The results of this study indicate that PIN diodes could be used in microdosimetry if the difference in the composition of tissue and silicon was kept in mind.

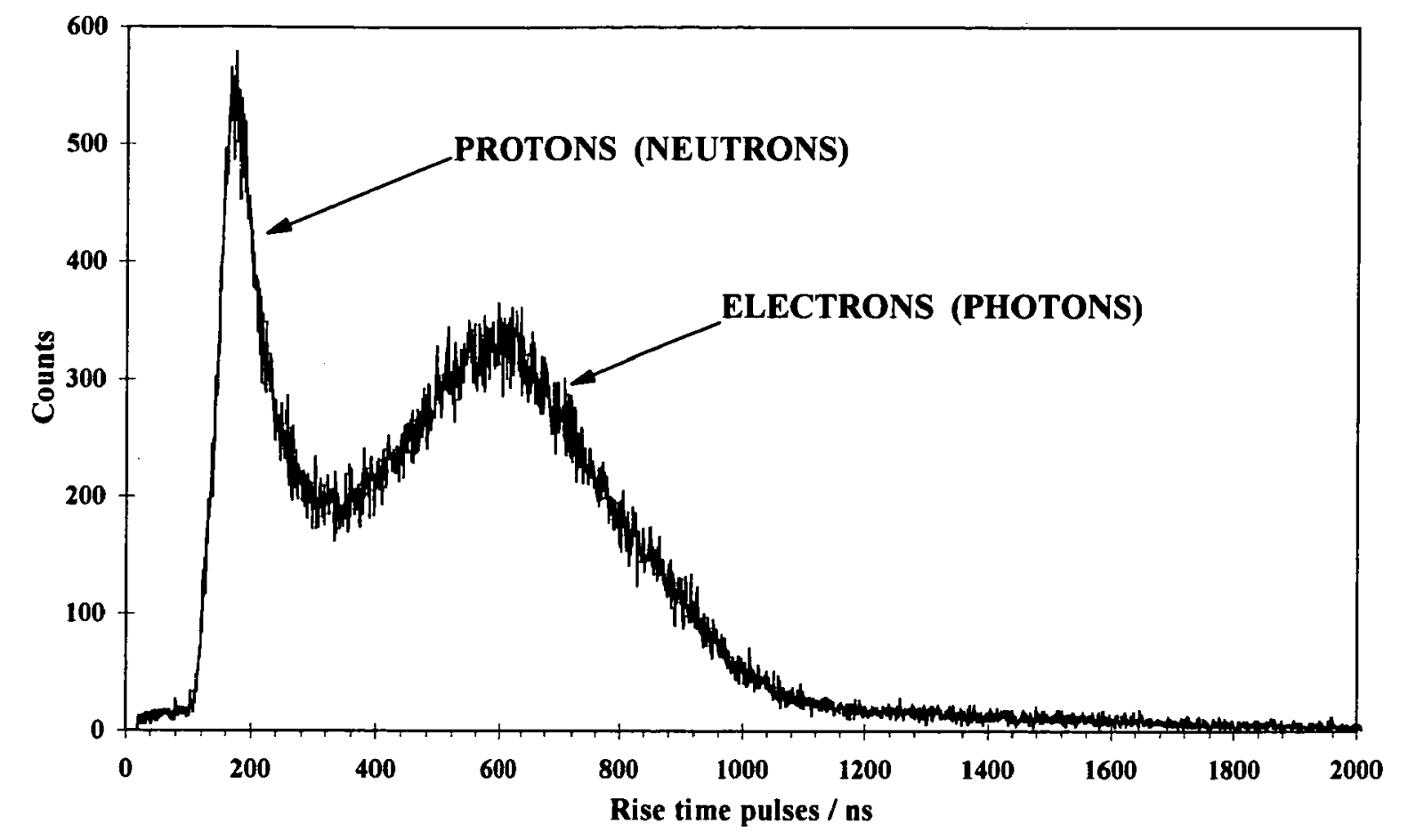

Fig. 8 - Rise time spectrum obtained in a silicon diode with an AmBe neutron source. Spectre des temps de montée obtenu avec un détecteur à diode en silicium en face d'une source de neutrons de type AmBe.

The streamer detector is based on the same principle as the diode detector; a gas streamer chamber is used instead of the silicon diode to detect secondary charged particles [16]. The converter is a polyethylene boron-loaded film surrounding the gas volume. A larger surface of exchange between the converter and the sensitive gas volume leads to a higher sensitivity to neutrons. The detector is less sensitive to gamma rays. A neutron to photon ratio, in terms of counts, of 200 can be achieved. Neutron to photon discrimination is accomplished by an electronic threshold on pulse height. The dose equivalent response of such a dosemeter to monoenergetic neutrons shows an increase by a factor of 5 between $73 \mathrm{keV}$ and $2.5 \mathrm{MeV}$ (Tab. I). 
TABLE I

Normalised neutron response in terms of $H_{p}(10)$ Réponse en équivalent de dose individuel normalisé à Punité à $2,5 \mathrm{MeV}$

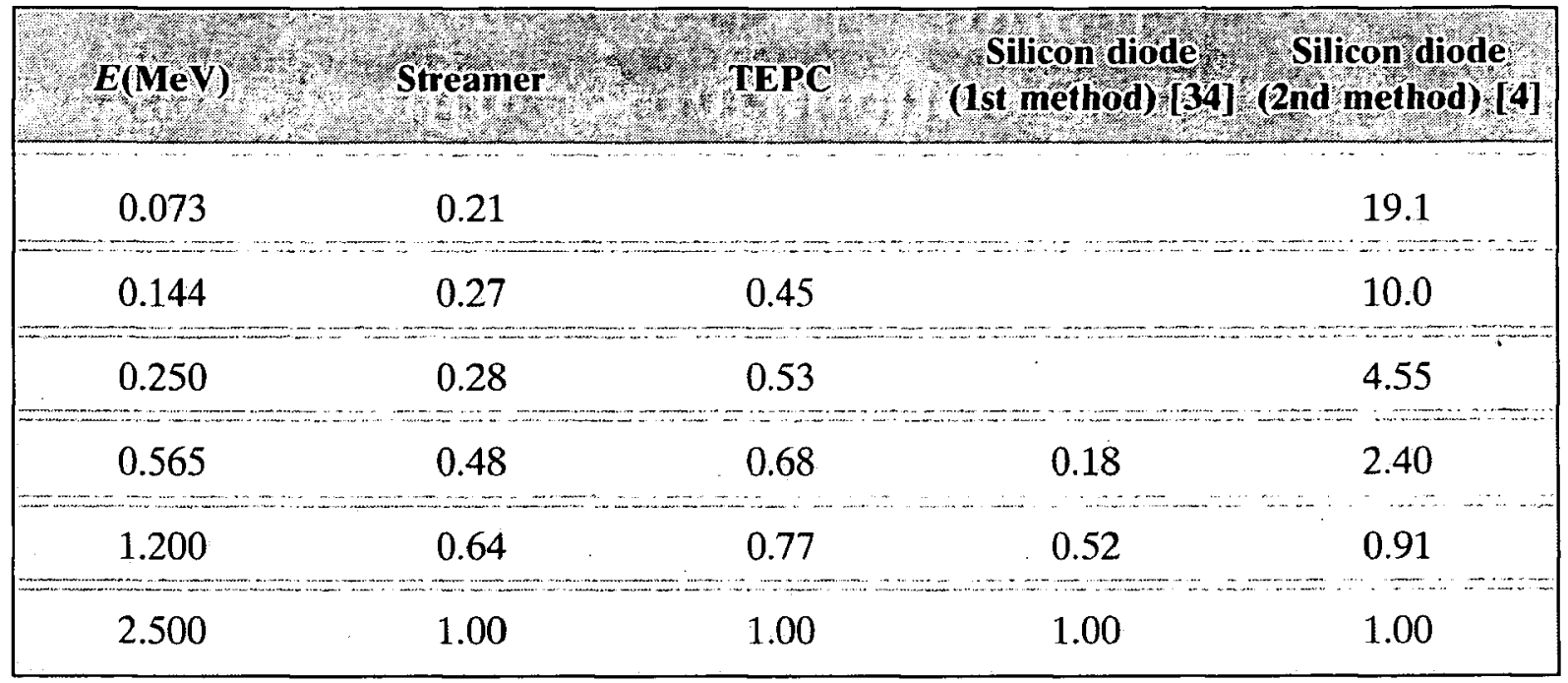

Streamer chambers and diode detectors are capable of providing information on dose equivalents, however, additional information on mean quality factors and absorbed doses may be needed. TEPCs are able to furnish these three quantities using the microdosimetric method (see Sect. 4.3). The application of TEPCs to personal dosimetry meets great difficulties, mainly because of the low sensitivity when classical (spherical or cylindrical) geometries with small volumes are concerned. This has led to a completely different design based on a multicellular geometry [24] by which the radiating surface of the cathode has been enlarged. Two flat cathodes have been used into which many channels were machined. However, an alpha calibration source cannot be used with this counter, and proton edge calibration is not possible in current low dose rate situations. Only external references such as cobalt gamma rays or neutron sources are therefore used. The results are comparable to those obtained with usual TEPCs for area monitoring. The energy dependence of the response reveals an underresponse at low energies $(E<1 \mathrm{MeV})$ due to microdosimetric assumptions (e.g. $y=L$, see Sect.4.3) and the lack of small events in this geometry. The sensitivities obtained are fully compatible with the requirements in individual monitoring. The most important problems for both sealed counters, streamer chamber and TEPC are the gas ageing effects. Work is in progress to reduce these parasitic effects.

\section{Conclusions}

The International commission on radiological protection (ICRP) recommends a decrease in the mean annual exposure limits by a factor of 2.5 and an increase in the radiation weighting factors for neutrons [45]. Both recommen- 
dations require the development of instruments of increased sensitivity [66]. In addition, during the past decade, the neutron energy range of practical relevance in radiation protection has been extended towards higher energies, i.e. $100 \mathrm{MeV}$ and even more. In this energy region, secondary protons and possibly other particles contribute to the long-range component of the radiation field, in addition to the "conventional" neutron-gamma components at neutron energies $<20 \mathrm{MeV}$.

In addition to developments in the "conventional" range, the future instrumentation in dosimetry and spectrometry should also take the requirements of increased sensitivity and/or extended energies into account. Experimental research must be complemented by a further development of the methods and of the data base for numerical dosimetry. Improved area monitoring, possibly including spectrometric capabilities, must be combined with optimum individual monitoring which means the use of active, directly readable compact instruments.

Finally, it is of great practical importance that dosimetry research for radiation protection purposes be targeted towards application in realistic, operational situations and that approaches be made with a view to enabling the transfer of research level methods to routine applications.

All these aspects demonstrate the need for further research and development work and a closer investigation of workplaces.

\section{REFERENCES}

[1] Alberts W.G., DieTZ E., GuldBAKKe S., KLUGE H., SCHUHMACHER $H$. - International intercomparison of TEPC systems used for radiation protection. Radiat. Prot. Dosim., 1989, 29, 47-53.

[2] ALBERTS W.G. (Ed.) - Investigation of individual neutron monitors on the basis of etched-track detectors: the 1990 EURADOS-CENDOS exercise. (PTB Report N10). Braunschweig: Physikalish-Technische Bundesanstalt, 1992.

[3] ALBERTS W.G., LUSZIK-BHADRA M., PIESCH E., VILGIS M. - Fast neutron dosimetry with CR-39: study of various materials using electrochemical etching. Nucl. Tracks Radiat. Meas., 1991, 19, 437-442.

[4] ALbERTS W.G., DiETZ E., GULDBAKKE S., KLUGE H. - Response of an electronic personal neutron dosemeter. Radiat. Protect. Dosim., 1994, 51, 207-210.

[5] AleVRA A.V., COSACK M., HUNT J.B., THOMAS D.J., SCHRAUBE H. Experimental determination of the response of four Bonner sphere sets to monoenergetic neutrons (II). Radiat. Prot. Dosim., 1992, 40, 91-102.

[6] ALEVRA A.V. - Accurate neutron fluence measurements using Bonner spheres. In : Reactor dosimetry (H. FARRAR IV, E.P. LIPPINCOT, J.G. WILLIAMS, D.W, VEHAR, Eds.) (ASTM STP 1228). Philadelphia, USA : American society for testing and materials (ASTM), 1994, 290-299. 
[7] ALEVRA A.V., KLEIN H., KNAUF K., WITTSTOCK J. -- Neutron field spectrometry for radiation protection dosimetry purposes. Radiat. Prot. Dosim., 1992, 44, 223-226.

[8] AlEVRA A.V., KLEIN H., SCHREWE U.J. - Measurements with the PTB Bonner sphere spectrometer in high energy neutron fields at CERN. (Report PTBN-22), Braunschweig: Physikalish-Technische Bundesanstall, 1994.

[9] ANDERSSON I.Ö., BRAUN J. - A neutron rem counter. Nucleonik, 1964, 6, 237.

[10] APFEL R.E., LO Y.-CH. - Practical neutron dosimetry with superheated drops. Health Phys., 1989, 56, 79-83.

[11] ARMiSHAW M.J., BUTLER J., CARTER M.D., CURL I.J., CRACKEN A.K. - A transportable neutron spectrometer (TNS) for radiological applications. Report AEEW-M 2365, Winfrith, UK, 1986.

[12] AROUA A., BOSCHUNG M., CARTIER F., GRECESCU M., PRETRE S., VALLEY J.F., WERNLI C. - Characterisation of the mixed neutron-gamma fields inside the Swiss nuclear power plants by different active systems. Radiat. Prot. Dosim., 1994, 51, 17-25.

[13] AROUA A., GRECESCU M., LAFRANCHI M., LERCH P., PRETRE S., VALLEY J.F. - Evaluation and test of the response matrix of a multipshere neutron spectrometer in a wide energy range. Part II : Simulation. Nucl. Instrum. Meth.,1992, A321, 305-311.

[14] AROUA A., HÖFERT M., SANNIKOV A., STEVENSON G.R. - Reference highenergy radiation fields at CERN. (Report CERN/TIS-RP/94-12/CF., Genève : CERN, 1994.

[15] BARElaud B., PAUl D., DUBARRY B., MAKOVICKA L., DECOSSAS J.L., VAREILLE J.C. - Principles of an electronic neutron dosemeter using a PIPS detector. Radiat. Protect. Dosim., 1992, 44, 363-366.

[16] BARTHE J., BORDY J.M., MOURGUES M., LAHAYE T., BOUTRUCHE B., SEGUR P. - New devices for individual neutron dosimetry. In : International workshop on individual monitoring, Villigen, 1993. Radiat. Protect. Dosim., 1994, 54, 365 368.

[17] BARTHE J., BORDY J.M., LAHAYE T., MOURGUES M. - New principle of single diode neutron dosemeter based on time resolution. In : Proceedings IRPA regional congress, Portsmouth, UK, 6-10 June 1994, 97-100.

[18] BARTLETT D.T., BRITCHER A.R., BARDELL A.G., THOMAS D.J., HUDSON I.F. - Neutron spectra, radiological quantities and instrument and dosemeter responses at a magnox reactor and a fuel reprocessing installation. Radiat. Prot. Dosim.,1992, 44, 233-238.

[19] BENNET E.F. - Proportional counter proton-recoil spectrometer with gamma discrimination. Rev. Sci. Instrum., 1962, 33, 1153-1160.

[20] BIRCH R. - An alpha-recoil proportional counter to measure neutron energy spectra between $2 \mathrm{Mev}$ and $15 \mathrm{MeV}$. Report AERE-R 13002, Harwell, UK, 1988.

[21] BIRCH R., DELAFIELD H.J., PERKS C.A. - Measurement of the neutron spectrum inside the containment building of a PWR. Radiat. Prot. Dosim., 1988, 23, 281284.

[22] BIRRATARI C., ESPOSITO A., FERRARI A., PELliCIONI M., SILARI M. - A neutron survey meter with sensitivity extended up to $400 \mathrm{MeV}$. Radiat. Prot. Dosim., 1992, 44, 193-197.

[23] BIRATTARI C., ESPOSITO A., FASSO A., FERRARI A., FESTAG J.G., HÖFERT M., NIELSEN M., PELLICCIONI M., RAFFNSOE CH., SCHMIDT P., SILARI M. - Intercomparison of the response of dosemeters used in high energy stray radiation fields. Radiat. Prot. Dosim., 1994, 51, 87-94. 
[24] BORDY J.M., BARTHE J., BOUTRUCHE B., SEGUR P. - A new proportional counter for individual neutron dosimetry, In : International workshop on individual monitoring, Villigen, 1993. Radiat. Prot. Dosim., 1994, 54, 369-372.

[25] BRAMBLETT R.L., EWING R.J., BONNER T.W. - A new type of neutron spectrometer. Nucl. Instrum. Meth., 1960, 9, 1-12.

[26] BUCKNER M.A., SIMS C.S., MILLER L.F. - Improving the performance of the combination personal neutron dosemeter. Radiat. Prot. Dosim., 1994, 51, 5-15.

[27] BURGKHADT B., FIEG E., PIESCH E., KLETT A., MAUSHART R. Optimization of a neutron dose equivalent measuring device (in German). In : Strahlenschutz: Physik und Meßtechnik (R. Maushart, H. Kölzer, Eds.). Köln: Verlag TÜV Rheinland, 1994, 590-595.

[28] BURGKHARDT B., PIESCH E., AL-JARALLAH M.I. - Neutron dose equivalent rate meter on the basis of the single sphere albedo technique. Radiat. Prot. Dosim., 1992, 44, 179-181.

[29] BURRUS W.P., VERBINSKI V.V. - Fast neutron spectroscopy with thick organic scintillators. Nucl. Instrum. Meth., 1969, 67, 181-196.

[30] CHARTIER J.L., POSNY F., BUXEROLlE M. - Experimental assembly for the simulation of realistic neutron spectra. Radiat. Prot. Dosim.,1992, 44, 125-130.

[31] DELAFIELD H.J., BIRCH R. - Neutron spectrometry measurements with large volume cylindrical proton-recoil counters developed for use in radiological protection. Report AERE-R 13103, Harwell, UK, 1989.

[32] d'ERRICO F., ALBERTS W.G. - Superheated-drop (bubble) neutron detectors and their compliance with ICRP-60. Radiat. Prot. Dosim., 1994, 54, 357-360.

[33] DINTER H., TESCH K. - Determination of neutron spectra behind lateral shielding of high energy proton accelerators. Radiat. Prot. Dosim., 1992, 42, 5-10.

[34] FERNANDEZ MORENO F. - Private communication, Autonomous Barcelona University, Physics Department, 08193 Bellaterra, Spain

[35] GIBSON J.A.B., PIESCH E. - Neutron monitoring for radiological protection (Technical reports series $n^{\circ} 252$ ). Vienna : IAEA, 1985.

[36] GIBSON J.A.B. - Individual neutron dosimetry. Radiat. Prot. Dosim., 1988, 23, 109115.

[37] GOLNIK N., ZIELCZYNSKI M. - Determination of ambient dose equivalent in mixed radiation fields by means of recombination chamber. In : Proceeding IRPA-8 congress, Montreal (Canada) May 1992, vol. 1, 156-159.

[38] GRIFFITH R.V. - Review of the state of the art in personnel neutron monitoring with solid state detectors. Radiat. Prot. Dosim., 1988, 23, 155-160.

[39] GRIFFITH R.V. - Individual neutron monitoring - needs for the nineties. Radiat. Prot. Dosim., 1992, 44, 259-266.

[40] GULDBAKKE S., JAHR R. - Neutron response of ion chamber photon dosemeters for neutron energies between $144 \mathrm{keV}$ and $15.5 \mathrm{MeV}$. In: Proceeding 5th symposium on neutron dosimetry (EUR 9762). Luxembourg : CEC, 1985, vol. II, 739-748.

[41] GULDBAKKE S., KLEIN H., MEISTER A., SCHELER U., UNHOLZER S., PULPAN J., TICHY M. - Response matrices of NE213 scintillation detectors for neutrons. In : Reactor dosimetry (H. FARRAR IV, E.P. LIPPINCOT, J.G. WILLIAMS, D.W. VEHAR, Eds.) (ASTM STP 1228). Philadelphia : ASTM, 1994, 290-299.

[42] HÖFERT M., PIESCH E. - Neutron dosimetry with nuclear emulsions. Radiat. Prot. Dosim., 1985, 10, 189-195.

[43] ING H., BIRNBOIM H.C. - A bubble-damage polymer detector for neutrons. Nucl. Tracks Radiat. Meas., 1984, 8, 285-288. 
[44] INTERNATIONAL COMMISSION ON RADIATION UNITS AND MEASUREMENTS (ICRU) - Quantities and units in radiation protection dosimetry (ICRU Report 51). Bethesda : ICRU, 1993.

[45] INTERNATIONAL COMMISSION ON RADIOLOGICAL PROTECTION (ICRP) - Recommendations... (ICRP Publication 60). Ann. ICRP, 1991, 21, (1-3).

[46] INTERNATIONAL STANDARDISATION ORGANISATION (ISO) - Neutron reference radiation for calibrating neutron-measuring devices used for radiation protection purposes and for determining their response as a function of neutron energy. (ISO 8529), Genève : ISO, 1989.

[47] INTERNATIONAL STANDARDISATION ORGANISATION (ISO) - Procedures for calibrating and determining the response of neutron measuring devices used for radiation protection (ISO/CD 10647). WD 8529-2 - Reference neutron radiations: dosimetry fundamentals related to the basic quantities characterising the radiation field. WD 8529-3 - Reference neutron radiations: calibration of area and personal dosemeters and the determination of their response as a function of energy and angle of incidence. Genève : ISO, 1994.

[48] JAHR R., HOLLNAGEL R., SIEBERT B.R.L. - Response of a system of two albedo dosemeters worn on chest and back in various distributed neutron fields. Radiat. Prot. Dosim., 1988, 23, 139-142.

[49] KADACHI A., WADEED A., OBEID M. - Performance of PIN photodiode in microdosimetry. Health Phys. 1994, 66(5), 577-580.

[50] KEMSHALL C.D. - The use of spherical proportional counters for neutron spectrometry measurements. Report AWRE 031/73, Harwell, 1973.

[51] KLEIN H., GULDBAKKE S., JAHR R., LESIECKI H. - The fast neutron sensitivity of a Geiger-Müller counter photon dosemeter by time-of-flight technique. Phys. Med. Biol., 1979, 24, 748-755.

[52] KNAUF K., ALEVRA A.V., KLEIN H., WITTSTOCK J. - Neutronenspektrometrie im Strahlenschutz. PTB-Mitteilungen, 1989, 99, 101-106 (see also EURATOM report EUR 13268, 1989, 133-142).

[53] LEAKE J.W. - An improved spherical dose equivalent neutron detector. Nucl. Instr. Meth., 1968, 63, 329.

[54] LUSZIK-BHADRA M., ALBERTS W.G., DIETZ E., GULDBAKKE S. - Aspects of combining albedo and etched track techniques for use in individual neutron monitoring. Radiat. Prot. Dosim., 1993, 46, 31-36.

[55] LUSZIK-BHADRA M., ALBERTS W.G., DIETZ E. GULDBAKKE S., KLUGE H. - A simple personal dosemeter for thermal, intermediate and fast neutrons based on CR-39 etched track detectors. Radiat. Prot. Dosim., 1992, 44, 313-316.

[56] LUSZIK-BHADRA M., ALBERTS W.G., D'ERRICO F., DIETZ E., GULDBAKKE S., MATZKE M. - A CR-39 track dosemeter for routine individual neutron monitoring. Radiat. Prot. Dosim., 1994, 55, 285-293.

[57] McELROY W.N., CROCKET T., HAWKINS R.G. - SAND-II, a computer automated method for neutron flux determination by foil activation. Report AFWL TR67, vol.I-IV, Air Force Weapons Laboratory, New Mexico, 1967.

[58] MARES V., SCHRAUBE H. - Evaluation of the response matrix of a Bonner sphere spectrometer with LiI detector from thermal energy to $150 \mathrm{MeV}$. Nucl. Instrum. Meth., 1994, A337, 461-473.

[59] MATZKE M., WEISE K. - Neutron spectrometry unfolding by Monte Carlo methods. Nucl. Instrum. Meth., 1985, A234, 324-330.

[60] MOURGUES M., CAROSSI J.C., PORTAL G. - A light rem-counter of advanced technology. In : Proceeding 5th symposium on neutron dosimetry (EUR $9762 \mathrm{EN}$ ). Luxembourg: CEC, 1985, 387-400. 
[61] NOLTE R., SCHUHMACHER H., BREDE H.J., SCHREWE U.J. - Measurements of high-energy neutron fluence with scintillation detector and proton recoil telescope. Radiat. Prot. Dosim., 1992, 44, 101-104 (see also report PTB-N-9, Braunschweig, 1993).

[62] ODA K., ITO M., YONEDA H., MIYAKE H., YAMAMOTO J., TSURUTAT. - Dose-equivalent response CR-39 track detector for personnel neutron dosimetry. Nucl. Instr. Meth., 1991, B61, 302-308.

[63] PEREY F.G. - Least squares dosimetry unfolding: the program STAY'SL. Report ORNL/TM-6062 ENDF-254, Oak Ridge, Tenn, 1977.

[64] PIESCH E., BURGKHARDT B. - Albedo dosimetry system for routine personnel monitoring. Radiat. Prot. Dosim., 1988, 23, 117-120.

[65] POLLOK R.W. - Current developments with bubble detectors. Nucl. Tracks Radiat. Meas., 1988, 15, 483-485.

[66] PORTAL G., DIETZE G. - Imṕlications of new ICRP and ICRU recommendations for neutron dosimetry. Radiat. Prot. Dosim., 1992, 44, 165-170.

[67] PORTAL G., BERMANN F., BUXEROLle M., MOURGUES M. - Neutron and photon radiation fields as encountered in practical radiation protection. Radiat. Prot. Dosim., 1985, 12, 193-201.

[68] POSNY F., CHARTIER J.L., BUXEROLLE M. - Neutron spectrometry system for radiation protection measurements at working places and in calibration fields. Radiat. Prot. Dosim., 1992, 44, 239-242.

[69] ROSPEC: Rotating neutron spectrometer (instruction manual). Chalk River, Canada : Bubble technology industries Inc., 1993.

[70] SCHRÖDER O., SCHMITZ T., PIERSCHEL M. - Microdosimetric dosemeters for individual monitoring based on semiconductor detectors. Radiat. Prot. Dosim., 1994, $52,431-434$.

[71] SCHUHMACHER H. - Tissue-equivalent proportional counters in radiation protection dosimetry: expectations and present state. Radiat. Prot. Dosim., 1992, 44, 199-206.

[72] SCHUHMACHER H., ALBERTS W.G. - Reference neutron fields with energies up to $70 \mathrm{MeV}$ for the calibration of radiation protection instruments. Radiat. Prot. Dosim., 1992, 42, 287-290.

[73] SCHUHMACHER H., SCHREWE U. - Dose equivalent measurements on board civil aircraft. (PTB Report PTB-N-13). Braunschweig: Physikalisch-Technische Bundesanstalt, 1993.

[74] SIEBERT B.R.L. - Radiation quantities: their interrelation. Radiat. Prot. Dosim., 1994, 54, 193-202.

[75] SIEBERT B.R.L., ALBERTS W.G. - The impact of recent ICRU and ICRP publications on radiation protection against neutrons. In : Proceedings 8 th International conference on radiation shielding, Arlington, USA (Texas), April 24-28, 1994. La Grange Park (USA) : American nuclear society, 1994, 25-32.

[76] SIEBERT B.R.L., SCHUHMACHER H. - Quality factors, ambient and personal dose equivalent for neutrons, based on the new ICRU stopping power data for protons and alpha particles. Radiat. Prot. Dosim., 1995, 58, 177-183.

[77] SIEBERT B.R.L., HOLLNA GEL R., JAHR R. - A theoretical concept for measuring doses from external radiation sources in radiation protection. Phys. Med. Biol., $1983,28,521-533$.

[78] SIEBERT B.R.L., SCHRAUBE H., THOMAS D.J. - A computer library of neutron spectra for radiation protection environments. Radiat. Prot. Dosim., 1992, 44, $135-137$. 


\section{NEUTRON DOSIMETRY}

[79] TANNER R.J., GILVIN P.J., STEELE J.D., BARTLETT D.T., WILLIAMS S.M. - The NRPB PADC neutron personal dosemeter: recent developments. Radiat. Prot. Dosim., 1990, 34, 17-20.

[80] WEISE K., WEYRAUCH M., KNAUF K. - Neutron response of a spherical proton recoil proportional counter. Nucl. Instrum. Meth., 1991, A309, 287-293.

[81] WERNLI C., BARTHE J., DIETZE G. - Individual dosimetry. Radioprotection, 1996, 31 (1), ce numéro, 17-35.

[82] WIEGEL B., ALEVRA A.V., SIEBERT B.R.L. - Calculations of the response functions of Bonner spheres with spherical ${ }^{3} \mathrm{He}$ proportional counter using a realistic detector model. Report PTB-N-21, Braunschweig: Physikalish-Technische Bundesanstalt, 1994. 